\title{
Circulating microRNAs: New biomarkers in diagnosis, prognosis and treatment of cancer (Review)
}

\author{
ALESSANDRO ALLEGRA $^{1}$, ANDREA ALONCI ${ }^{1}$, SALVATORE CAMPO $^{2}$, GIUSEPPA PENNA $^{1}$, \\ ANNAMARIA PETRUNGARO $^{1}$, DEMETRIO GERACE ${ }^{1}$ and CATERINA MUSOLINO ${ }^{1}$ \\ ${ }^{1}$ Division of Hematology, University of Messina; ${ }^{2}$ Department of Biochemical, Physiological and Nutritional Sciences, \\ Section of Medical Chemistry, School of Medicine, University of Messina, I-98125 Messina, Italy
}

Received June 19, 2012; Accepted August 16, 2012

DOI: $10.3892 /$ ijo.2012.1647

\begin{abstract}
MicroRNAs (miRNAs) are small non-coding, endogenous, single-stranded RNAs. MiRNAs have been implicated in different areas such as the immune response, neural development, DNA repair, apoptosis, oxidative stress response and cancer. However, while the majority of miRNAs are found intracellularly, a significant number of miRNAs have been observed outside of cells, including various body fluids. Circulating miRNAs function as 'extracellular communication RNAs' that play an important role in cell proliferation and differentiation. MiRNA regulation is essential to many cellular processes, and escape from this regulatory network seems to be a common characteristic of several disease processes and malignant transformation. The interest in circulating miRNAs reflects in fact their central role in regulation of gene expression and the implication of miRNA-specific aberrant expression in the pathogenesis of cancer, cardiac, metabolic, neurologic, immune-related diseases as well as others. In our review we aimed to summarize the data related to the action of cellular miRNAs on the onset of various diseases, thus bringing together some of the latest information available on the role of circulating miRNAs. Additionally, the role of circulating miRNAs could be particularly relevant in the context of neoplastic diseases. At least 79 miRNAs have been reported as plasma or serum miRNA biomarkers of solid and hematologic tumors. Circulating miRNA profiling could improve the diagnosis of cancer, and could predict outcome for cancer patients, while the profiling of alterations in circulating miRNA that may signal a predisposition to cancer, could also be a therapeutic target in these patients.
\end{abstract}

Correspondence to: Professor Caterina Musolino, Division of Hematology, University of Messina, Via Consolare Valeria, I-98125 Messina, Italy

E-mail: cmusolino@unime.it

Key words: circulating microRNAs, cellular microRNAs, non-coding RNA, cancer, extracellular communication RNAs, gene expression

\section{Contents}

1. General considerations on cellular miRNAs

2. Circulating miRNAs: the new frontier of the intercellular communication

3. Circulating miRNAs in health and disease

4. Circulating miRNAs in autoimmune diseases, inflammatory and metabolic disorders

5. Cellular and circulating miRNAs in neoplastic diseases

6. Specific patterns of circulating miRNAs in cancer patients

7. Limits and challenges of circulating miRNAs

8. Future perspectives for circulating miRNAs

9. Conclusions

\section{General considerations on cellular miRNAs}

MicroRNAs (miRNAs) are smal, typically 22 nucleotides, noncoding (nc), endogenous, single-stranded RNAs. Until recently, the central dogma of genetics was that RNA played the role of messenger between the gene and the final proteins encoded by the gene, and ncRNAs were ignored in the field of genome sequencing. Before the discovery of miRNAs, it was known that a large part of the genome is not translated into proteins. This so called 'junk' DNA was thought to be evolutionary debris with no real function. Recently, the explosion in research in this area has established miRNAs as powerful regulators of gene expression. Genome-wide transcriptional analyses have estimated that most transcribed mammalian genomic sequences are ncRNAs (1-6). While only about 1,424 human miRNA sequences have been identified so far, genomic computational analysis indicates that as many as 50,000 miRNAs may exist in the human genome, and each may have multiple targets based on similar sequences in the 3'-UTR of mRNA. In fact, it has been estimated that more than $60 \%$ of mammalian mRNAs are targeted by at least one miRNA (7).

MiRNAs were first identified in Caenorhabditis elegans in the early 1990s (8), but have since been reported in a wide variety of organisms ranging from single-cell algae to humans, suggesting that miRNA-mediated biological function is an ancient and critical cellular regulatory system $(9,10)$. The importance of miRNA function is further suggested by the extreme evolutionary conservation of both individual miRNA sequences 
and the miRNA processing machinery. MiRNA genes are evolutionarily conserved and are located within the introns or exons of protein-coding genes, as well as in intergenic areas. In addition, the number of miRNAs in the genome appears to be correlated with the complexity of the developmental program, with mammals having the largest number of miRNAs.

MiRNAs are transcribed in much the same way as proteincoding genes. The majority of miRNAs are transcribed by RNA polymerase II (11), though a minor fraction of miRNAs are transcribed by RNA polymerase III (12). These primary miRNA transcripts (pri-miRNAs) are often several hundred nucleotides long and are modified similarly to protein-coding transcripts by the addition of a $5^{\prime}$ cap and a $3^{\prime}$ poly-A tail. Pri-miRNAs are then processed first in the nucleus and later in the cytosol by the RNase III enzymes Drosha and Dicer, respectively. This sequential processing of pri-miRNAs first yields a miRNA precursor (pre-miRNA) of $\sim 70$ nucleotides in length, and eventually a mature double-stranded miRNA of 19-24 nucleotides. Typically, one strand of this mature miRNA duplex, termed the guide strand, associates with the RNA-induced silencing complex (RISC). While it is generally believed that upon incorporation into the RISC complex, the other strand (the passenger strand) is unwound from the guide strand and degraded, there is evidence that in some cases, both strands of the miRNA duplex are functional (13). MiRNA-RISC complexes interact with mRNA targets through partial sequence complementation, typically within the 3 ' untranslated region of target mRNAs. It is thought that the extent of base pairing between the miRNA and its mRNA target determines whether the mRNA is degraded or translationally repressed (14).

MiRNAs have been implicated in different areas such as the immune response, neural development, DNA repair, apoptosis, and oxidative stress response. It is surprising the list of diseases which have been found to be associated with abnormal miRNA expression. Moreover, several authors have focused their attention on the importance of cancer regulator miRNAs. They are divided into oncomiRs and anti-oncomiRs that negatively regulate tumor suppressor genes and oncogenes, respectively. Importantly, the association of miRNAs with cancer has prompted their potential relevance in cancer diagnosis, prognosis and treatment (15).

\section{Circulating miRNAs: the new frontier of intercellular communication}

If the discovery of miRNAs by Ambros and colleagues in 1993 introduced another level of intricacy in the regulation of the genome (8), the discovery of circulating miRNAs highlighted the possibility of new mediators of gene regulation. In fact, while the majority of miRNAs are found intracellularly, a significant number of miRNAs have been observed outside of cells, including in various body fluids (16-20). These miRNAs are stable and show distinct expression profiles in different fluid types. Given the instability of most RNA molecules in the extracellular environment, the presence and apparent stability of miRNAs here is surprising. Serum and other body fluids are known to contain ribonucleases (21), which suggests that secreted miRNAs are likely packaged in some manner so to protect them against RNase digestion. MiRNAs could be shielded from degradation by packaging in lipid vesicles, in complexes with RNA-binding proteins, or both $(22,23)$. Despite accumulating evidence for the presence of miRNAs in body fluids, the origin and the function of these circulating extracellular miRNAs remains poorly understood. One of the more interesting ideas is that extracellular miRNAs are used as mediators of cell-cell communication (24-26). If this is the case, then certain miRNAs are presumably targeted for export in one cell, and can be recognized, taken up, and utilized by another. The presence of miRNAs in body fluids may represent an infinite resource of non-invasive biomarkers in cancer $(27,28)$. Recent studies have also identified miRNAs in two types of cell-derived lipid vesicles; microvesicles and exosomes. Microvesicles are relatively large $(100 \mathrm{~nm}-1 \mu \mathrm{m})$ vesicles released from the cell through blebbing. Exosomes, on the other hand, are smaller vesicles $(30-100 \mathrm{~nm})$ released when endosomally-derived multivesicular bodies fuse with the plasma membrane. MiRNAs have been identified in both exosomes and microvesicles derived from a variety of sources, including human and mouse mast cells, glioblastoma tumors (29), plasma (30), saliva (31) and urine (32).

Studies have suggested that exosomes can be secreted by many cells, including T cells, B cells, mast cells, dendritic cells, cancer cells and macrophages (33-37). Probably most of the circulating miRNAs are found in exosomes, which protect them from degradation and are responsible for their excellent stability $(23,30,38)$. Exosomes can be transferred from one cell to another, and their components can function in the new environment. Much work has focused on understanding the mechanisms of exosome-mediated cell-cell interactions (39). Some of these interactions involve communication between different cell types and convey regulatory effectors $(40,41)$; whereas, others occur among cells of the same type (42). It was found that endogenous plasma miRNAs exist in a form that is resistant to $4^{\circ} \mathrm{C}$ or $37^{\circ} \mathrm{C}$ incubation, freeze-thaw cycles, and even to RNase activity (43).

Circulating miRNAs are surprisingly tractable. Some of the key molecular properties of these species include high stability in circulation and the ability to survive unfavorable physiological conditions such as extreme variations in $\mathrm{pH}$ and multiple freeze thaw cycles $(18,23,44,45)$. However, although, exosomal miRNA has been hypothesized to be involved in intercellular communication $(18,23,46)$ it remains unclear whether all extracellular miRNAs are associated with exosomes and whether extracellular miRNA are present in physiologically relevant amounts for cell-to-cell signaling. A different study has indicated that cells in culture predominantly exported miRNA in exosome-independent form (30). In fact, Turchinovich et al have shown that the overwhelming majority of the nuclease-resistant extracellular miRNA in plasma and cell culture media is floating outside exosomes and is bound to Ago 2 protein - a part of the RNA-induced silencing complex. They also found indications that extracellular miRNA can be bound to other Ago proteins (especially Ago1). However, it is possible that parts of extracellular circulating miRNAs are by-products of dead or dying cells that persist due to the high stability of the miRNA/Ago2 complex (47). As has already been said, circulating miRNAs are not only abundant in blood, but are also very stable, which are important prerequisites for clinical biomarkers. Chen et al (48) treated miRNAs with RNase A digestion. Surprisingly, more than half of the miRNAs remained intact after $3 \mathrm{~h}$ of exposure to 
RNase A. Furthermore, circulating miRNAs remain stable after being subjected to harsh conditions including boiling, low/high $\mathrm{pH}$, and extended storage (49). Circulating mature miRNA in contrast to mRNA is strikingly stable in blood plasma and cell culture media. The high stability of miRNAs constitutes an enormous advantage from a clinical diagnostic point of view as it allows an efficient isolation from clinical specimens including sputum (50), plasma $(44,51,52)$, and serum $(48,53)$. Finally, miRNA signatures in blood are similar in men and women, as well as individuals of different ages (30). Together, these results indicate that circulating miRNAs have many characteristics of ideal biomarkers, most notably their inherent stability and resilience.

\section{Circulating miRNAs in health and disease}

Several studies have compared the expression profiles of hundreds of blood-borne miRNAs across a variety of nonmalignant and malignant diseases to identify disease-specific expression patterns. The resulting miRNA expression data could be used to discriminate disease samples with a high level of accuracy, demonstrating the potential for using microRNA signatures for the blood-based diagnosis of disease (54). The ability to profile miRNAs in circulation, thus provides a noninvasive opportunity to investigate disease-specific miRNAs and represents an exciting alternative approach to current strategies for cancer surveillance.

\section{Circulating miRNAs in autoimmune diseases, inflam- matory and metabolic disorders}

Before we cover extensively the role of miRNAs in the pathogenesis and diagnosis of cancer, we can briefly summarize the action of miRNAs in non-cancer diseases, in order to fully understand the extension of their role in pathophysiological mechanisms. A promising field of research for the use of miRNAs as markers of disease is definitely one constituted by autoimmune diseases. Wang et al studied the serum and urinary level of several circulating miRNA species (miR-200 family, miR-205 and miR-192) in patients with systemic lupus erythematosus (SLE) and compared them with that of healthy controls. The serum levels of miR-200a, miR-200b, miR-200c, miR-429, miR-205 and miR-192, and urinary miR-200a, miR-200c, miR-141, miR-429 and miR-192 of SLE patients were lower than those of controls. Glomerular filtration rate (GFR) correlated with serum miR-200b, miR-200c, miR-429, miR-205 and miR-192; proteinuria inversely correlated with serum miR-200a and miR-200c. SLE disease activity index (SLEDAI) inversely correlated with serum miR-200a. Serum miR-200b and miR-192 correlated with platelet count, while serum miR-205 correlated with red cell count and hematocrit (55). But a prognostic significance can be assigned to the circulating microRNAs also in autoimmune pathologies of a different type. Michael et al extracted miRNAs from exosomes obtained from the saliva of patients with Sjögren's syndrome (31), while, although many cellular miRNA expressions appear to be involved in the development of less serious immunologic diseases such as allergic rhinitis (56), no study has confirmed a different pattern of circulating miRNAs in these types of patients.
Several studies have instead pointed out an altered expression of circulating miRNA in inflammatory diseases such as Chron's disease and sarcoidosis. A survey of miRNA levels in the sera of control and patients with Chron's disease (CD) detected significant elevation of 24 miRNAs, 11 of which were chosen for further validation. All of the candidate biomarker miRNAs were confirmed in an independent CD sample set. To explore the specificity of the CD-associated miRNAs, they were measured in the sera of patients with celiac disease; none were changed compared with healthy controls. Receiver operating characteristic analyses revealed that serum miRNAs have promising diagnostic utility, with sensitivities for $\mathrm{CD}$ above $80 \%$. Of particular interest is the data that indicate significant decreases in serum miRNAs observed in patients with pediatric CD after 6 months of treatment (57). Moreover, peripheral blood miRNAs could be used to distinguish active CD and ulcerative colitis (UC) from healthy controls. Five miRNAs were significantly increased and two miRNAs (149* and miRplus-F1065) were significantly decreased in the blood of active CD patients as compared to healthy controls. Twelve miRNAs were significantly increased and miRNA-505* was significantly decreased in the blood of active UC patients as compared to healthy controls. Ten miRNAs were significantly increased and one miRNA was significantly decreased in the blood of active UC patients as compared to active CD patients (58). However, peripheral blood miRNAs can be developed as unique biomarkers that are reflective and predictive of metabolic health and disorder. It has been reported that miRNAs circulating in the blood can potentially serve as novel non-invasive biomarkers of diseases including diabetes (59). Karolina et al have in fact, identified signature miRNAs which could possibly explain the pathogenesis of T2D and the significance of miR-144 in insulin signaling. Increased circulating level of miR-144 has been found to correlate with down-regulation of its predicted target, insulin receptor substrate 1 (IRS1) at both mRNA and protein levels. They also experimentally demonstrated that IRS1 is indeed the target of miR-144 (60).

Circulating microRNA expression profiles may be promising biomarkers for diagnosis and assessment of the prognosis of neurologic diseases as well. Cogswell et al recovered miRNAs from cerebrospinal fluid and discovered Alzheimer's disease (AD)-specific miRNA changes consistently with their role as potential biomarkers for the disease (61), while it was identified that miR-137, miR-181c, miR-9, miR-29a/b miRNAs were down-regulated in the blood serum of probable AD patients. The levels of these miRNAs were also reduced in the serum of AD risk factor models. Although the ability of these miRNAs to conclusively diagnose AD is currently unknown, it was suggested as a potential use for circulating miRNAs, along with other markers, as non-invasive and relatively inexpensive biomarkers for the early diagnosis of AD (62). However, circulating mRNAs could be useful in a complex neuropsychiatric disorder that involves disturbances in neural circuitry and synaptic function as in schizophrenia. The capacity for discreet post-synaptic remodeling of neurons requires coordination by an elaborate intracellular network of molecular signal transduction systems. The redundancy of these networks means that many combinations of gene variants have the potential to cause system dysfunction that manifest as related neurobehavioural syndromes. Recent investigation has 
Table I. Circulating miRNAs in non-neoplastic diseases.

\begin{tabular}{llll}
\hline Disease & \multicolumn{1}{c}{ miRNA } & Variation & \multicolumn{1}{c}{ Significance } \\
\hline Systemic lupus erythematosus & $\begin{array}{l}\text { miR-200a, 200b, 200c, 205, 429, 192 (serum) } \\
\text { miR-200a, 200c, 141, 429,192 (urinary) } \\
\text { miR-149, plusF1065 }\end{array}$ & Reduced & $\begin{array}{l}\text { Correlation with GFR, proteinuria, } \\
\text { and SLE disease activity index }\end{array}$ \\
Chron disease & miR-505 & Reduced & Reduced \\
Ulcerative colitis & miR-144 & Increased & Correlation with insulin receptor \\
Diabetes & miR-137, 181c,9,29a/b & substrate 1 \\
Alzheimer's disease & miR-1, 133a, 206 & Reduced & Markers of early disease \\
Duchenne muscular dystrophy & Increased & Experimental models \\
Preeclampsia & miR-210 & Increased & Reduced \\
\end{tabular}

revealed that post-transcriptional gene regulation and associated small non-coding miRNA are likely to be important factors that shape the topography of these networks. MiRNA display complex temporal spatial expression patterns in the mammalian brain and have the potential to regulate thousands of target genes by functioning as the specificity factor for intracellular genesilencing machinery. They are emerging as key regulators of many neurodevelopmental and neurological processes such as in the pathophysiology of schizophrenia as their dysregulation could lead to pervasive changes in the network structure during development and in the mature brain. Furthermore, modification of miRNAs could be found not only in the cerebral cortex but at a peripheral level as well (63). Finally, circulating mRNAs could be used as biomarker in Duchenne muscular dystrophy (DMD), a lethal X-linked disorder caused by mutations in the dystrophin gene, which encodes a cytoskeletal protein, dystrophin. Creatine kinase (CK) is generally used as a bloodbased biomarker for muscular disease including DMD, but it is not always reliable since it is easily affected by stress to the body, such as exercise. The expression levels of specific serum circulating miRNAs may be useful to monitor the pathological progression of muscular diseases. Mizuno et al found that the serum levels of several muscle-specific miRNAs (miR-1, miR-133a and miR-206) are increased in both dystrophindeficient muscular dystrophy mouse model and canine X-linked muscular dystrophy in Japan dog model. Interestingly, unlike CK levels, expression levels of these miRNAs in mdx serum are only slightly influenced by exercise when using treadmill. These results suggest that serum miRNAs are useful and reliable biomarkers for muscular dystrophy (64). Laterza et al have demonstrated that aberrant expression of circulating miRNAs corresponds to the origin of tissue injury (65). Circulating miRNAs are in fact biomarkers for diverse cardiovascular diseases, including acute myocardial infarction, heart failure, coronary artery disease, stroke, essential hypertension, and acute pulmonary embolism (66). But circulating miRNAs seem to be able to regulate various physiological processes such as pregnancy. It is in fact well known that maternal plasma miRNA expression profiles dynamically change during pregnancy. The results of function analysis suggested that miRNAs may play an important role in regulating pregnancy process, which can help us understand the refined regulatory mechanism in pregnancy
(67). It has also been shown that placenta-associated circulating miRNAs correlate with pregnancy progression (68). Even more relevant could be the circulating mRNAs profile, in that it could be useful to predict pregnancy-related disease such as preeclampsia, which continues to be a fatal disease among pregnant women. Gunel et al found up-regulated miR-210 levels as well as down-regulated miR-152 levels in preeclampsia patients (69) (Table I).

\section{Cellular and circulating miRNAs in neoplastic diseases}

Cellular miRNAs in oncologic patients. Since cellular miRNAs play a fundamental role in regulation of a variety of cellular, physiological, and developmental processes, it is easy to understand that their aberrant expression can lead to a variety of human diseases including cancer. A number of cellular miRNAs were shown in fact to be located in fragile regions of the human genome that are associated with cancer (70), and dysregulated miRNAs have been shown to play a crucial role in tumor initiation, progression, and metastasis, and are often associated with diagnosis, prognosis, and response to therapy (71-73) (Table II). Lu et al developed a method for bead-based miRNA profiling. Employing this technique on twenty different cancers, they found that each cancer had a specific miRNA profile and that most poorly-differentiated tumors could be classified to their tissues of origin based on their miRNA expression levels (74). Among their functional roles, cellular miRNAs regulate in fact development, organogenesis, hematopoiesis, and cell proliferation, and they can intervene with various mechanisms in the genesis of neoplastic disease can acting on apoptosis, angiogenesis, and neoplastic microenvironment.

Several studies have pointed out the action of cellular miRNA on the onset of cancer, and miRNA-21 is one of the most prominent miRNAs implicated in the genesis and progression of human cancer. The earliest study showed that miRNA-21 is commonly and markedly up-regulated in human glioblastoma, and inhibition of miRNA-21 expression leads to caspase activation and associated apoptotic cell death in multiple glioblastoma cell lines (75). Subsequently, there is a growing body of evidence to prove that miRNA-21 is overexpressed in a variety of tumors such as breast cancer (75), lung cancer (76), colon cancer, and $\mathrm{HCC}$, with proproliferative and anti-apoptotic function (77-80). 
Table II. Cellular miRNAs in cancer diseases.

\begin{tabular}{|c|c|c|}
\hline Tumor type & miRNAs & Expression \\
\hline Glioblastoma & 21 & $\begin{array}{l}\text { Down-regulation } \\
\text { Overexpressed }\end{array}$ \\
\hline Breast cancer & $\begin{array}{l}\text { 193b, Let-7, 29, 200/141 } \\
21,155,17-92\end{array}$ & $\begin{array}{l}\text { Down-regulation } \\
\text { Overexpressed }\end{array}$ \\
\hline Lung cancer & $\begin{array}{l}486-5 p, \text { let- } 7,29 \\
21,155,17-92\end{array}$ & $\begin{array}{l}\text { Down-regulation } \\
\text { Overexpressed }\end{array}$ \\
\hline Colon cancer & $\begin{array}{l}34 \\
21,31,155\end{array}$ & $\begin{array}{l}\text { Down-regulation } \\
\text { Overexpressed }\end{array}$ \\
\hline $\mathrm{HCC}$ & 21 & $\begin{array}{l}\text { Down-regulation } \\
\text { Overexpressed }\end{array}$ \\
\hline Tongue & 31 & $\begin{array}{l}\text { Down-regulation } \\
\text { Overexpressed }\end{array}$ \\
\hline $\begin{array}{l}\text { Gastric } \\
\text { cancer }\end{array}$ & $\begin{array}{l}31,192,215,200 / 141 \\
21\end{array}$ & $\begin{array}{l}\text { Down-regulation } \\
\text { Overexpressed }\end{array}$ \\
\hline $\begin{array}{l}\text { Urothelial } \\
\text { cancer }\end{array}$ & 31 & $\begin{array}{l}\text { Down-regulation } \\
\text { Overexpressed }\end{array}$ \\
\hline $\begin{array}{l}\text { Bladder } \\
\text { cancer }\end{array}$ & $\begin{array}{l}143,145 \text { (CAFs), } 200 / 141 \\
16,320 \text { (CAFs) }\end{array}$ & $\begin{array}{l}\text { Down-regulation } \\
\text { Overexpressed }\end{array}$ \\
\hline $\begin{array}{l}\text { Endometrial } \\
\text { cancer }\end{array}$ & $\begin{array}{l}503,424,29 b, 146 a, \\
31 \text { (CAFs) }\end{array}$ & $\begin{array}{l}\text { Down-regulation } \\
\text { Overexpressed }\end{array}$ \\
\hline $\begin{array}{l}\text { Pancreatic } \\
\text { cancer }\end{array}$ & $18 \mathrm{a}, 21$ & $\begin{array}{l}\text { Down-regulation } \\
\text { Overexpressed }\end{array}$ \\
\hline $\begin{array}{l}\text { Testicular } \\
\text { cancer }\end{array}$ & 372,373 & $\begin{array}{l}\text { Down-regulation } \\
\text { Overexpressed }\end{array}$ \\
\hline Lymphomas & $155,17-92$ & $\begin{array}{l}\text { Down-regulation } \\
\text { Overexpressed }\end{array}$ \\
\hline LLC & $\begin{array}{l}15 \mathrm{a}, 16-1,29 \\
155,21\end{array}$ & $\begin{array}{l}\text { Down-regulation } \\
\text { Overexpressed }\end{array}$ \\
\hline AML & $\begin{array}{l}29 \\
155,21, \text { let-7, 126, 196b }\end{array}$ & $\begin{array}{l}\text { Down-regulation } \\
\text { Overexpressed }\end{array}$ \\
\hline ALL & 128 & $\begin{array}{l}\text { Down-regulation } \\
\text { Overexpressed }\end{array}$ \\
\hline
\end{tabular}

HCC, hepatocellular carcinoma; CLL, chronic lymphocytic leukemia; AML, acute myeloid leukemia; ALL, acute lymphoblastic leukemia.

Up-regulation of miRNA-31 was found in colon cancer and squamous cell carcinomas of the tongue. Interestingly, in colon cancer studies not only was miRNA-31 up-regulated but this up-regulation was found to be associated with poorer clinical outcomes and increased invasiveness (81-84). However, there is some support for down-regulation of miRNA-31 in gastric cancer, and urothelial cancers (85-88). Moreover a comparison of miRNAs and mRNA profiles of primary and metastatic cancer lesions showed that miRNAs provided a more reliable and distinctive signature than mRNAs and found that miRNA signatures were superior to mRNAs in identifying the organ source of metastases of unknown origin $(74,89)$. As for the action of cellular miRNAs on apoptosis, it is well known that miRNA-195 is an important member of the micro$15 / 16 / 195 / 424 / 497$ family, and which is activated in multiple diseases, such as cancers. MiRNA-195 regulates a plethora of target proteins, which are involved in the cell cycle, apoptosis, proliferation. WEE1, CDK6, and Bcl-2 are confirmed target genes of miRNA-195 that are involved in miRNA-195-mediated cell-cycle and apoptosis processes effects (90). Moreover, Donzelli et al showed that p53R175H, a hotspot p53 mutant, induces miRNA-128-2 expression. Mutant $\mathrm{p} 53$ binds to the putative promoter of miR-128-2 host gene, ARPP21, determining a concomitant induction of ARPP21 mRNA and miRNA-128-2. MiRNA-128-2 expression in lung cancer cells inhibits apoptosis and confers increased resistance to cisplatin, doxorubicin and 5-fluorouracil treatments. At the molecular level, miRNA-128-2 post-transcriptionally targets E2F5 and leads to the abrogation of its repressive activity on p21(waf1) transcript. The p21(waf1) protein localizes to the cytoplasmic compartment, where it exerts an anti-apoptotic effect by preventing pro-caspase-3 cleavage (91). It is also well known that a tumor needs to grow its own vasculature. The miRNA-17-92 cluster is highly expressed in human endothelial cells that participate in angiogenesis. Yin et al showed that miRNA-19b-1, a component of this cluster, controls the intrinsic angiogenic activity of human umbilical vein endothelial cells (HUVECs) in vitro. In silico and in vitro analyses have suggested that miRNA-19b-1 targets mRNA corresponding to the pro-angiogenic protein, FGFR2, and blocks the cell cycle from the $\mathrm{S}$ phase to the $\mathrm{G} 2 / \mathrm{M}$ phase transition by controlling the expression of cyclin D1. Thus, miRNA-19b-1 may serve as a valuable therapeutic agent in the context of tumor angiogenesis (92). Finally, it is possible that cellular miRNAs can create better conditions for the growth of the tumor. A recent bladder cancer study has identified specific miRNA profiles in cancer-associated fibroblasts (CAFs) (93). These studies observed an increase in miRNA-16 and miRNA-320 in CAFs in comparison to normal bladder fibroblasts. It is possible that the up-regulated miRNAs in CAFs facilitate tumor survival or progression. In contrast to the up-regulated miRNAs, miRNA-143 and miRNA-145 are downregulated in CAFs compared to foreskin fibroblasts. There was no significant decrease in miRNA-143 and miRNA-145 between CAFs and normal bladder fibroblasts, however, although a trend was reported. Previous studies in bladder cancer have shown decreased levels of miRNA-145 correlated with a decrease in apoptotic ability suggesting that a decrease in miRNA-145 in CAFs may also contribute to evasion of apoptosis in the microenvironment (94-97). Another study looking at different CAF cell lines from endometrial cancers identified several differentially expressed miRNAs in the CAFs in comparison to normal fibroblasts (18). These included increased expression of miRNA-503, miRNA-424, miRNA-29b and miRNA-146a, and miRNA-31 (98).

A number of target genes for miRNA-31 are involved in cellular movement, cytoskeletal organization, phagocytosis, transport, cellular transformation, anchorage-independence, and chromatin remodelling such as CCNJ, ELAVL1, ENY2, RHOBTB1, CLASP2, VAMP4, STX12, TACC2, and SATB2. In any case it has been confirmed that cellular miRNAs are involved in the development of a variety of tumors, such as 
leukemia, neuroblastoma, pituitary adenoma, breast cancer, thyroid cancer, hepatocarcinoma, colorectal cancer, and lung cancer. The up- or down-regulation of different miRNAs in these tumor tissues were found with most of the miRNA targets located in regions of tumor related genome such as fragile sites, loss of heterozygosity, and amplified regions, thereby exhibiting the same effect as oncogenes or tumor suppressor genes $(70,99)$. Bullock et al demonstrated their importance in the early stages of the metastatic cascade. An important event in the metastatic cascade is epithelial to mesenchymal transition (EMT), a reversible phenotypic switch over, which endows malignant epithelial cells with the capacity to break free from one another and invade the surrounding stroma. Their understanding of EMT has been significantly improved by the characterization of miRNAs that influence the signalling pathways and downstream events that define EMT on a molecular level (100). In addition, miRNAs were prognostic indicators in colon cancer patients (52), while miRNA expression differentiates histology and predicts survival and relapse of lung cancer (101-103) (Table II).

Circulating miRNA and cancer. Circulating miRNAs have been implicated in regulation of stem cells as well as cancer stem cells. Given that cancer stem cells are believed to be responsible for the cancer initiation, metastasis, and chemotherapy resistance, a better understanding of how circulating miRNAs mediate gene expression in cancer stem cells will help identify novel cancer biomarkers and therapeutic targets (Table III). As a result, it will aid in the development of better strategy for cancer treatment (104). Mitchell et al demonstrated the presence of circulating tumor-derived miRNAs in blood by using a mouse prostate cancer xenograft model system and showed that measurements obtained from plasma were strongly correlated with those obtained from sera, suggesting that both serum and plasma samples would be adequate for measuring specific miRNA levels (44). In another study, Chen et al demonstrated that by using serum directly or by extracting RNA from the serum they could identify unique miRNA expression profiles for lung cancer, and colorectal cancer patients compared with healthy subjects (48). Circulating miRNAs have also been postulated as novel biomarkers for ovarian cancer, pancreatic cancer and colorectal cancer $(38,52,105-107)$. Although the clinical significance of these findings has not been elucidated in detail, those findings demonstrated that circulating miRNAs could be non-invasive diagnostic or prognostic markers for cancer. We might wonder what could be the mechanism by which circulating miRNAs can exert their action. It was pointed out that there must be some method of communication between the cancer cells and their microenvironment. The dynamic crosstalk between cancer cells and normal cells in the microenvironment is a crucial point in the progression of disease. One manner of cell-cell communication is through the secretion of molecules and paracrine signaling. Molecules of secretion are no longer limited to cytokines, chemokines, growth factors, and other protein molecules, but now include miRNA species (108).

Observations that miRNAs act as mediators of heterotypic signaling in the tumor stroma and ECM could provide researchers with a novel target for such therapies. Given their biological importance, it is not surprising that circulating miRNA expression is frequently dysregulated in human cancer. Accumulating evidence suggests that circulating miRNAs can
Table III. Circulating miRNAs in cancer diseases.

\begin{tabular}{|c|c|c|}
\hline Tumor type & Expression & miRNAs \\
\hline Prostate & $\begin{array}{l}\text { Reduced } \\
\text { Increased }\end{array}$ & $\begin{array}{l}\text { 16, 92a, 103, 107, 197, 485-3p, } \\
\text { 486-5p, 26a, 92b, 574-3p, 636, } \\
640,766,885-5 p, 141,195 \\
\text { leti, 375, 298, } 346\end{array}$ \\
\hline Breast cancer & $\begin{array}{l}\text { Reduced } \\
\text { Increased }\end{array}$ & $10 b, 34 a, 195$, let-7, 223 \\
\hline Ovarian cancer & $\begin{array}{l}\text { Reduced } \\
\text { Increased }\end{array}$ & $\begin{array}{l}155,127,99 b \\
21,141,200 a, 200 b, 200 c, 203 \\
205,214\end{array}$ \\
\hline Lung cancer & $\begin{array}{l}\text { Reduced } \\
\text { Increased }\end{array}$ & $\begin{array}{l}486-5 \mathrm{p}, 146 \mathrm{~b}, 221,17-5 \mathrm{p}, 106 \mathrm{a} \\
\text { let-7b,223 } \\
7 \mathrm{i}, 206,21,30 \mathrm{~d}, 1,491,210,10 \mathrm{~b} \\
34 \mathrm{a}, 141,155,197,182,29 \mathrm{c}\end{array}$ \\
\hline $\begin{array}{l}\text { Colorectal } \\
\text { cancer }\end{array}$ & $\begin{array}{l}\text { Reduced } \\
\text { Increased }\end{array}$ & $17-3 p, 92 a, 29 a, 141$ \\
\hline Oral cancer & $\begin{array}{l}\text { Reduced } \\
\text { Increased }\end{array}$ & $\begin{array}{l}125 a, 200 a \text { (saliva) } \\
31,24\end{array}$ \\
\hline $\begin{array}{l}\text { Hepatocellular } \\
\text { carcinoma }\end{array}$ & $\begin{array}{l}\text { Reduced } \\
\text { Increased }\end{array}$ & $21,122,34 \mathrm{a}, 16$ \\
\hline $\begin{array}{l}\text { Pancreatic } \\
\text { cancer }\end{array}$ & $\begin{array}{l}\text { Reduced } \\
\text { Increased }\end{array}$ & 155 (pancreatic juice), 18 \\
\hline $\begin{array}{l}\text { Biliary tract } \\
\text { cancer }\end{array}$ & $\begin{array}{l}\text { Reduced } \\
\text { Increased }\end{array}$ & 9,145 (bile) \\
\hline $\begin{array}{l}\text { Oesophageal } \\
\text { carcinoma }\end{array}$ & $\begin{array}{l}\text { Reduced } \\
\text { Increased }\end{array}$ & $\begin{array}{l}375 \\
21\end{array}$ \\
\hline Gastric cancer & $\begin{array}{l}\text { Reduced } \\
\text { Increased }\end{array}$ & $187,371-5 p, 378$ \\
\hline Renal cancer & $\begin{array}{l}\text { Reduced } \\
\text { Increased }\end{array}$ & 1233 \\
\hline Lymphoma & $\begin{array}{l}\text { Reduced } \\
\text { Increased }\end{array}$ & $21,155,210$ \\
\hline $\begin{array}{l}\text { Chronic } \\
\text { lymphocytic } \\
\text { leukemia }\end{array}$ & $\begin{array}{l}\text { Reduced } \\
\text { Increased }\end{array}$ & $\begin{array}{l}195,29 a, 222,20 a, 150,451 \\
135 a, 486-5 p\end{array}$ \\
\hline $\begin{array}{l}\text { Acute myeloid } \\
\text { leukemia }\end{array}$ & $\begin{array}{l}\text { Reduced } \\
\text { Increased }\end{array}$ & 92 \\
\hline $\begin{array}{l}\text { Myelodisplastic } \\
\text { syndrome }\end{array}$ & $\begin{array}{l}\text { Reduced } \\
\text { Increased }\end{array}$ & Let7a, 16 \\
\hline $\begin{array}{l}\text { Multiple } \\
\text { myeloma }\end{array}$ & $\begin{array}{l}\text { Reduced } \\
\text { Increased }\end{array}$ & $148 \mathrm{a}, 181 \mathrm{a}, 20 \mathrm{a}, 221,625,99 \mathrm{~b}$ \\
\hline
\end{tabular}

contribute to tumorigenesis either by directly modulating oncogenic or tumor suppressor pathways and/or being regulated by oncogenes or tumor suppressor genes. To date more than several tens of cancer have been investigated in which expression profiling of circulating miRNAs have revealed both diagnostic and prognostic utility for this class of biomarkers $(109,110)$, and 
several authors recently showed that aberrant plasma expressions of miRNAs could distinguish cancer patients from healthy individuals $(43,50,111,112)$ (Table III).

\section{Specific patterns of circulating miRNAs in cancer patients}

Lung cancer. It is well known that up-regulation of cellular miRNA-21 leads to tumor development and progression $(75,113,114)$, but circulating miRNA-21 has also been described as a biomarker for different tumor entities $(115,116)$. For instance, it was recently found that miRNA-21 was one of plasma miRNAs that could differentiate early stage lung cancer patients from healthy non-smoking individuals (117). In a recent study, miRNA-21 and miRNA-210 display higher plasma expression levels, whereas miRNA-486-5p has lower expression level in patients with malignant solitary pulmonary nodules (SPNs), as compared to subjects with benign SPNs and healthy controls. A logistic regression model with the best prediction was built on the basis of miR-21, miR-210, and miR-486-5p. The three miRNAs used in combination produced the area under receiver operating characteristic curve at 0.86 in distinguishing lung tumors from benign SPNs with $75.00 \%$ sensitivity and $84.95 \%$ specificity. Validation of the miRNA panel in the testing set confirms their diagnostic value that yields significant improvement over any single one (117). All these data were confirmed by other studies. Plasma miRNA-21 levels were in fact significantly higher in NSCLC patients than in age and sex matched controls, and were related to TNM stage, but not related to age, sex, smoking status, histological classification, lymph node status, and metastasis. Importantly, miRNA-21 plasma levels in partial response samples were several folds lower than that in stable disease plus progressive disease samples, and were close to that in healthy controls. In such a case, plasma miRNA-21 can serve not only as a circulating tumor biomarker for the early diagnosis of NSCLC, but also to the sensitivity of platinum based chemotherapy (118).

A different promising miRNA is miRNA-486-5p that was shown to regulate tumor progression and OLFM4 anti-apoptotic factor (119). Furthermore, cellular miRNA-486-5p was under expressed in several types of solid tumors and in lung cancer $(120,121)$. Several studies showed that plasma miRNA-486-5p expression in lung cancer patients is significantly lower compared to subjects with both benign SPNs and healthy smokers. The findings in both surgical tissues and plasma specimens suggest that miRNA-486-5p down-regulation might play a role as a tumor suppressor in lung tumorigenesis $(117,122)$. The concentrations of four circulating microRNAs (miRNA-10b, miRNA-34a, miRNA-141 and miR-RNA155) significantly discriminated cancer patients from healthy individuals. The levels of miRNA-10b, miRNA-141 and miRNA-155 were significantly higher in lung cancer patients than those in patients with benign disease. In lung cancer patients high serum miRNA-10b values associated with lymph node metastasis and elevated levels of TPA (tissue polypeptide antigen), whereas high serum miR-141 values associated with elevated levels of uPA (urokinase plasminogen activator) (123). A significant correlation between circulating miRNA and stage disease was pointed out by Zheng et al that found that the levels of miR-155, miR-197, and miR-182 in the plasma of lung cancer including stage I patients were significantly elevated compared with controls. The combination of these 3 miRNAs yielded $81.33 \%$ sensitivity and $86.76 \%$ specificity in discriminating lung cancer patients from controls. The levels of miR-155 and miR-197 were higher in the plasma from lung cancer patients with metastasis than in those without metastasis and were significantly decreased in responsive patients during chemotherapy (124). Different findings are reported by Heegaard et al that found that the expression of miRNA-146b, miRNA-221, let-7a, miRNA-155, miRNA-17-5p, miRNA-27a and miRNA-106a were significantly reduced in the serum of NSCLC cases while miRNA-29c was significantly increased. No significant differences were observed in plasma of patients compared to controls. Overall, expression levels in serum did not correlate well with levels in plasma. In secondary analyses, reduced plasma expression of let- $7 \mathrm{~b}$ was modestly associated with worse cancer-specific mortality in all patients and reduced serum expression of miR-223 was modestly associated with cancer-specific mortality in stage IA/B patients (125). Finally of extreme interest could be the datum that Bianchi et al developed a test, based on the detection of 34 miRNAs from serum, that could identify patients with early stage non-small cell lung carcinomas (NSCLCs) in a population of asymptomatic high-risk individuals with $80 \%$ accuracy. The signature could assign disease probability accurately either in asymptomatic or symptomatic patients, distinguish between benign and malignant lesions, and capture the onset of the malignant disease in individual patients over time (126).

Breast cancer. Analyses of cellular miRNA profiles in breast cancer have determined that many miRNAs display expression patterns linked to molecular subtype (127-130) as well as ER status, tumor grade (128), and other tumor-related processes (131-133). Experimental evidence has confirmed that miRNA levels can play a role in determining disease course; for example, re-expression of miRNA-193b, down-regulated in highly metastatic derivatives of the MDA-MB-231 cell line, significantly inhibited tumor growth and dissemination in a mouse xenograft model. Thus, integrated analysis of miRNA in breast cancer constitutes an important new frontier (134). Yan et al found that overexpression of miR21 in breast cancer is associated to lymph node metastasis and poor prognosis (85). Roth and colleagues reporting the findings of altered tumor specific miRNAs in sera of breast cancer patients, while Mitchell et al has previously demonstrated that circulating miRNAs that are elevated in breast cancer patients when the tumor is in situ (miR-195 and let-7a) decrease to basal levels by 2 weeks post-tumor resection $(44,110,135)$. Recent data have demonstrated that macrophages are able to produce microvesicles, which shuttle proteins or miRNAs into adjacent cells within the microenvironment (23,25,136-139). Yang et al demonstrated that exogenous miRNAs transfected into IL-4-activated M2 macrophages can be shuttled into co-cultivated breast cancer cells in the absence of direct cell-cell contact with the macrophages. Exosomes containing miRNA-223 were released by M2 cells and were then internalized by co-cultivated breast cancer cells that did not express this miRNA. The exosome-shuttled miR-223 promoted the invasiveness of breast cancer cells in vitro. This process of invasion could be inhibited by transfecting miRNA-223 antisense oligonucleotides (ASO) into the tumor cells. The above provides evidence for the delivery of invasion-potentiating miRNA-223 by IL-4-activated macrophages to breast cancer 
cells via exosomes and may highlight a novel communication mechanism between TAMs (tumor-associated macrophages) and cancer cells (140).

Patients with liver damage and hepatocellular carcinoma. In chronic hepatitis $\mathrm{C}$ infection (CHC) patients and in patients with NAFLD (non-alcoholic fatty-liver disease), plasma levels of miR-122 were elevated compared to healthy controls. In CHC patients, miR-122 levels correlated with fibrosis stage and inflammation activity but did not correlate with $\mathrm{HCV}$ viral load (141-145). In hepatocellular carcinoma patients, plasma miRNA-21 level was measured by qRT-PCR before and after curative resection of hepatocellular carcinoma. Plasma miRNA-21 was also compared in other groups of patients with chronic hepatitis, and healthy volunteers. Plasma miRNA-21 level in the patients with hepatocellular carcinoma was significantly higher than in patients with chronic hepatitis and healthy volunteers. In the patient group after resection of the carcinoma, plasma miRNA-21 levels significantly diminished after surgery compared with the pre-operative values. ROC analysis of plasma miRNA-21 yielded an AUC of 0.773 with $61.1 \%$ sensitivity and $83.3 \%$ specificity when differentiating hepatocellular carcinoma from chronic hepatitis, and an AUC of 0.953 with $87.3 \%$ sensitivity and $92.0 \%$ specificity when differentiating hepatocellular carcinoma from healthy volunteers. Both sets of values were superior to $\alpha$-fetoprotein and improved for the combination of miRNA-21 and $\alpha$-fetoprotein (146). Plasma miRNA-21 level remains as a promising biochemical marker for hepatocellular carcinoma and liver damage, although Cermelli et al found that whereas miR-21 extracellular levels were unchanged, extracellular levels of miR-122, miR-34a and to a lesser extent miR-16, steadily increased during the course of liver damage (147). MiR-122 in serum was significantly higher in HCC patients than healthy controls. More importantly, it was found that the levels of miRNA-122 were significantly reduced in the post-operative serum samples when compared to the preoperative samples. Although serum miR-122 was also elevated in HBV patients with HCC comparing with those without HCC, the difference was at the border line ( $\mathrm{p}=0.043)(148)$.

Pancreatic cancer. Aberrant expression of miRNAs is associated with phenotypes of various cancers, including pancreatic cancer (PaC). However, the mechanism of the aberrant expression is largely unknown. Activation of the mitogen-activated protein kinase (MAPK) signaling pathway plays a crucial role in gene expression related to the malignant phenotype of pancreatic cancer. Ikeda et al studied the role of MAPK in the aberrant expression of miRNAs in pancreatic cancer cells. They found that the cellular miRNAs, miRNA-7-3, miRNA-34a, miRNA-181d, and miRNA-193b, were preferentially associated with MAPK activity. Among these miRNAs, miRNA-7-3 was up-regulated by active MAPK, while the others were downregulated. Promoter assays indicated that the promoter activities of the host genes of miRNA-7-3 and miRNA-34a were both down-regulated by alteration in MAPK activity. Exogenous overexpression of the MAPK-associated miRNAs had the effect of inhibition of the proliferation of cultured $\mathrm{PaC}$ cells; miRNA-193b was found to exhibit the most remarkable inhibition (149). Regarding circulating miRNAs, the comparative analysis of miRNA expression during malignant progression in the mouse model allows to draw some conclusions about relevant miRNAs in the circulation that can indicate the presence of precursor lesions. Habbe et al (150) reported on the expression levels of miRNAs in human intraductal papillary mucinous neoplasms (IPMN) tissues and in pancreatic juice samples, and concluded that miRNA-155 is up-regulated and a possible tissue biomarker of pre-invasive disease. La Conti et al reported that changes in miRNA expression patterns during progression of normal tissues to invasive pancreatic adenocarcinoma in the p48-Cre/LSL-Kras ${ }^{\mathrm{G} 12 \mathrm{D}}$ mouse model mirrors the miR changes observed in human PaC tissues. MiRNA-148a/b and miRNA-375 expressions were found decreased whereas miRNA-10, miRNA-21, miRNA-100 and miRNA-155 were increased when comparing normal tissues, premalignant lesions and invasive carcinoma in the mouse model. Predicted target mRNAs FGFR1 (miRNA-10) and MLH1 (miRNA-155) were found to be down-regulated. Quantitation of nine microRNAs in plasma samples from patients distinguished pancreatic cancers from other cancers as well as non-cancerous pancreatic disease. Finally, gemcitabine treatment of control animals and p48-Cre/LSL-Kras ${ }^{\mathrm{G} 12 \mathrm{D}}$ animals with pancreatic cancer caused distinct and up to 60-fold changes in circulating miRNAs that indicate differential drug effects on normal and cancer tissues (151). MiRNA-18a is located in the miRNA-17-92 cluster and reported to be highly expressed in $\mathrm{PaC}$ tissues. The expression of miRNA-18a was significantly higher in pancreatic cancer tissues and pancreatic cancer cell lines than in normal tissues and fibroblasts. Moreover, plasma concentrations of miRNA-18a were significantly higher in $\mathrm{PaC}$ patients than in controls. Plasma levels of miRNA-18a were significantly lower in postoperative samples than in preoperative samples (152). Several other studies confirmed the relevance of circulating miRNAs in $\mathrm{PaC}$ cancer patients. Seven miRNAs displayed significantly different expression levels in $\mathrm{PaC}$ compared with controls. This serum 7-miRNA-based biomarker had high sensitivity and specificity for distinguishing various stages of $\mathrm{PaC}$ from cancerfree controls and also accurately discriminated $\mathrm{PaC}$ patients from chronic pancreatitis $(\mathrm{CP})$ patients. Among the 7 miRNAs, miRNA-21 levels in serum were significantly associated with overall $\mathrm{PaC}$ survival. The diagnostic accuracy rate of the serum 7-miRNA profile was $83.6 \%$ in correctly classifying 55 cases with clinically suspected $\mathrm{PaC}$ (153). Hwang et al retrospectively studied the effect of miRNA-21 on the chemotherapy efficacy and prognosis of $\mathrm{PaC}$ : patients with low expression of miRNA-21 have significantly prolonged overall and disease-free survival after chemotherapy; antisense inhibition of miRNA-21 can enhance chemotherapeutic sensitivity. MiRNA-21 may be related to platinum sensitivity. The high expression of plasma miRNA-21 may also be involved in cell resistance to platinum chemotherapy. Inhibiting miRNA-21 expression is likely to restore cell sensitivity to platinum chemotherapy (154).

Biliary tract cancer (BTC): miRNA in body fluids. Beside the possibility of assessing the serum or plasma circulating concentrations of miRNAs, as has already been mentioned, the possibility to dose such markers in other body fluids exists. This is especially true in patients with biliary cancers in which the evaluation can be carried out in the bile. Shigehara et al sampled bile from patients who underwent biliary drainage for biliary diseases such as BTC and choledocholithiasis. PCR-based 
miRNA detection and miRNA cloning were performed to identify bile miRNAs. Using high-throughput real-time PCR-based miRNA microarrays, the expression profiles of 667 miRNAs were compared in patients with malignant disease and age-matched patients with the benign disease choledocholithiasis. They subsequently characterized bile miRNAs in terms of stability and localization. Through cloning and using PCR methods, they confirmed that miRNAs exist in bile. Differential analysis of bile miRNAs demonstrated that 10 of the 667 miRNAs were significantly more highly expressed in the malignant group than in the benign group. Setting the specificity threshold to $100 \%$ showed that some miRNAs (miRNA-9, miRNA-302c ${ }^{*}$, miRNA-199a-3p and miRNA-222*) had a sensitivity level of $88.9 \%$, and receiveroperating characteristic analysis demonstrated that miRNA-9 and miRNA- $145^{*}$ could be useful diagnostic markers for BTC. Moreover, they verified the long-term stability of miRNAs in bile, a characteristic that makes them suitable for diagnostic use in clinical settings. These findings suggest that bile miRNAs could be informative biomarkers for hepatobiliary disease and that some miRNAs, particularly miR-9, may be helpful in the diagnosis and clinical management of BTC (155).

Upper digestive tract: oesophageal carcinoma and gastric cancer. The plasma level of miRNA-21 was significantly higher and that of miRNA-375 was significantly lower in oesophageal squamous cell carcinoma (ESCC) patients than controls. The high plasma miRNA-21 levels reflected tumor levels in all cases $(100 \%)$. The plasma level of miRNA-21 was significantly reduced in postoperative samples. The miRNA-21/miRNA-375 ratio was significantly higher in ESCC patients than in controls. Patients with a high plasma level of miRNA-21 tended to have greater vascular invasion and a high correlation with recurrence (156).

Several authors have studied expression levels of cellular miRNAs in patients with gastric cancer (GC). In fact, miRNA192 and miRNA-215 were down-regulated in MGC-803 cells, BGC-823 cells and SGC-7901 cells. The down-regulation of miRNA-192 and miRNA-215 was also demonstrated to be associated with increased tumor sizes. Moreover, the expression of miRNA-192 was significantly lower in the pT4 stage of gastric cancer than in pT1, pT2 and pT3 stages. Furthermore, there was a strong correlation between miR-192 and miR-215 in gastric cancer tissues. MiRNA-192 and miRNA-215 might be related to the proliferation and invasion of GC (157). Cellular miRNAs can modify invasion of cancer cells with a negative effect on metastatic phenomena (158). Concerning the circulating miRNAs, Liu et al showed that serum miRNA-378 could serve as a novel non-invasive biomarker in GC detection. Genome-wide miRNA expression profiles followed with real-time quantitative RT-PCR (qRT-PCR) assays revealed that miRNA-187*, miRNA-371-5p and miRNA-378 were significantly elevated in GC patients. Further validation indicated that miRNA-378 alone could yield a ROC curve area of 0.861 with $87.5 \%$ sensitivity and $70.73 \%$ specificity in discriminating GC patients from healthy controls (159).

Colorectal cancer. The high expression of cellular miRNA-21 in patients with colorectal cancer (CRC) is correlated to clinical stage, lymph node metastasis, and distant metastasis (82). MiRNA-34a, a transcriptional target of p53, is a well-known tumor suppressor gene. Wu et al identified Fra-1 as a new target of miRNA-34a, and demonstrated that miRNA-34a inhibits Fra-1 expression at both protein and mRNA levels. In addition, they found that p53 indirectly regulates Fra-1 expression via a miRNA-34a-dependent manner in colon cancer cells. Overexpression of miR-34a strongly inhibited colon cancer cell migration and invasion, which can be partially rescued by forced expression of the Fra-1 transcript lacking the 3'-UTR. Moreover, they found that miRNA-34a was down-regulated in 25 of $40(62.5 \%)$ colon cancer tissues, as compared to the adjacent normal colon tissues, and that the expression of miRNA-34a was correlated with the DNA binding activity of p53 $(160,161)$. Cheng et al found that circulating miRNA-141 was significantly associated with stage IV colon cancer in a cohort of 102 plasma samples. Receiver operating characteristic analysis was used to evaluate the sensitivity and specificity of candidate plasma miRNA markers. They observed that combination of miRNA-141 and carcinoembryonic antigen (CEA), a widely used marker for CRC, further improved the accuracy of detection. Furthermore, their analysis showed that high levels of plasma miRNA-141 predicted poor survival in both cohorts and that miR-141 was an independent prognostic factor for advanced colon cancer. They propose that plasma miRNA-141 may represent a novel biomarker that complements CEA in detecting colon cancer with distant metastasis and that high levels of miRNA-141 in plasma were associated with poor prognosis (162). A different circulating miRNA was found altered in colon cancer patients. MiRNA-92 levels were in fact significantly higher in plasma samples from patients than in healthy controls and can be a potential marker for CRC detection (107).

Renal cell ccarcinoma and prostate cancer. Although 109 miRNAs were circulating at higher levels in cancer patients' serum, Wulfken et al identified only few miRNAs with up-regulation in renal cell carcinoma (RCC) tissue and serum of RCC patients. A multicentre cohort of RCC patients and healthy controls using quantitative real-time PCR (sensitivity $77.4 \%$, specificity $37.6 \%$ ) shows miRNA-1233 was increased in RCC patients. They also studied samples of patients with angiomyolipoma or oncocytoma, whose serum miRNA-1233 levels were similar to RCC patients. However, circulating miRNAs were not correlated with clinicopathological parameters (163). Mahn et al instead analyzed circulating miRNAs in serum as non-invasive biomarker in patients with localized prostate cancer (PCA), benign prostate hyperplasia (BPH) and healthy individuals (HI). Circulating oncogenic miRNA levels were different, and especially the miRNA-26a level allowed sensitive (89\%) discrimination of PCA and BPH patients at a moderate specificity [56\%; area under the curve (AUC): 0.703]; the analysis of oncogenic miRNAs in combination increased the diagnostic accuracy (sensitivity: 78.4\%; specificity: 66.7\%; AUC: 0.758). Despite the small number of patients limiting the statistical power of the study, they observed correlations with clinicopathologic parameters: miRNA-16, miRNA-195, and miRNA-26a were significantly correlated with surgical margin positivity; miRNA-195 and miRNA-let7i were significantly correlated with the Gleason score. Tissue miRNA levels were correlated with preprostatectomy miRNA levels in serum, and serum miRNA decreased after prostatectomy, thereby indicating tumor-associated release of miRNA (164). Moreover, 
recent reports found that some circulating prostate cancerassociated miRNAs such as miRNA-375 and miRNA-141, correlate with risk of disease progression and other predictors of disease outcome, such as Gleason score and lymph node status, highlighting the prognostic potential of this class of molecules (44,116,165-167). Wach et al used an autochthonous transgenic model of prostate cancer, transgenic adenocarcinoma of mouse prostate (TRAMP), to discover prostate cancer-associated miRNAs in serum. They showed that the levels of miR-141, miR-298 and miR-375 were increased in localized primary tumors and metastases. They proposed that these miRNAs are expressed in prostate cancer cells and released into surrounding blood vessels during disease progression. Interestingly, miR-346 was elevated in the serum of men with mCRPC but reduced in metastases in the MSKCC cohort. This tissue-associated loss appears to be a consequence of enhanced release of microvesicle-encapsulated miRNAs. Thus, hsa-miR-346 export from prostate cancer cells may be augmented without a change in expression of the hsa-miR-346 gene, leading to it being progressively lost in malignant tissue while it accumulates in the blood (168-170). However, expression of both miR-141 and miR-375 was correlated with risk of biochemical relapse. Moreover, Cox proportional hazards regression and $\mathrm{C}$-statistics revealed that miR-375 possesses prognostic potential that is independent from Gleason score. Therefore, the capacity of tumor and/or serum levels of miR-141 and miR-375 to predict prostate cancer recurrence is quite interesting. Given the association of hsa-miR-141 and hsa-miR-375 with biochemical relapse, it was hypothesized that they could have direct roles in prostate cancer pathophysiology by deregulating normal gene expression. Analysis of the predicted gene targets of these miRNAs revealed enrichment of many pathways likely to be important in prostate cancer. Furthermore, preliminary bioinformatic analyses revealed that 4 genes, SPAG9, SOCS5, MBNL1 and MTPN, were downregulated in prostate tumors and inversely correlated with levels of miR-141 and miR-375, suggesting that they are targets of these miRNAs (171).

As circulating miRNA-141 is detected in plasma of patients with PCa, several authors compared the temporal changes of miR-141 with the levels of CTC, LDH, and PSA in patients with $\mathrm{PCa}$, and longitudinally examined these markers alone or in combinations to determine the utility of miR-141 in the predicting a patient's clinical course and response to therapy. A total of 35 intervals were assessed. Directional changes (increasing or decreasing) in PSA, CTC, and miR-141 had sensitivity in predicting clinical outcome (progression vs. non-progressing) of $78.9 \%$. Logistic regression modeling of the probability of clinical progression demonstrates that miR-141 levels predicted clinical outcomes with an odds ratio of at least 8.3. MiR-141 also had the highest correlation with temporal changes of PSA. In this retrospective study, miR-141 demonstrated a similar ability to predict clinical progression when compared with other clinically validated biomarkers. Furthermore, miR-141 demonstrated high correlation with changes of the other biomarkers (172).

Salivary miRNAs and oral cancer detection. Up-regulation of hsa-miR-24 and hsa-miR-31 has been found in squamous cell carcinoma of the oral cavity (173), while decreased levels of miR-125a and miR-200a in saliva are associated with the same disease (174).
Hematologic neoplasias. One area of great interest for use in diagnostic, prognostic and therapeutic of circulating miRNAs is certainly hemopoiesis and hematologic diseases. The patients with diffuse large B cell lymphoma (DLBCL) had high serum levels of miRNA-21, which was associated with improved relapse-free survival (30). This result is consistent with previous findings in biopsy material from a different cohort of DLBCL patients, where high tumor miR-21 expression was also associated with a more favorable clinical outcome. Moreover, elevated levels of miR-155, and miRNA-210 were found in serum of patients with diffuse large B cell lymphoma (175). Why high levels of miRNA-21 should be associated with a more favorable clinical outcome for DLBCL patients remains to be determined. Although miRNA-21 has been found to have an anti-proliferative effect in some cancers (177), the opposite appears to be true for other cancers (176). Presumably it is the targeting of oncogenes and/or antiapoptotic molecules by miRNA-21 that is important in determining clinical outcome in DLBCL patients.

LLC. Calin et al (70) were the first to show that their cellular miRNA microarray could differentiate between B cell chronic lymphocyte leukemia (CLL) cells and normal cells. Furthermore, they classified CLL samples into two different groups based on their miRNA profiles, and these profiles corresponded to high or low levels of a protein that is associated with a positive prognosis at low levels. One commonly observed chromosomal aberrations in CLL is the deletion of chromosomal 13q14.3, a region containing miR-15a and miR-16, which suggests, but does not prove, the involvement of miRNAs in the pathogenesis of CLL. In addition, an aberrant cellular miRNA expression profile in CLL B cells has been described and the changes correlate well with prognostic factors including ZAP-70 expression status and $\mathrm{IgV}_{\mathrm{H}}$ mutations in CLL patients. Recent studies also demonstrated the decrease of miR-29c and miR-223 levels in cells during the progression of the disease (178).

Moussay et al showed that circulating miRNAs could also be sensitive biomarkers for CLL, because certain extracellular miRNAs are present in CLL patient plasma at levels significantly different from healthy controls and from patients affected by other hematologic malignancies. The levels of several of these circulating miRNAs also displayed significant differences between zeta-associated protein 70 (ZAP-70) ${ }^{+}$and ZAP-70- CLL. The changes of circulating miR-195 (AUC $=0.951)$ or miR-20a $(\mathrm{AUC}=0.920)$ levels were the best classifiers to separate CLL patients from healthy controls. They tested the possibility of improving performance by combining the changes of several miRNAs. When 14 miRNAs were combined, the AUC value derived from a standard principal component analysis and ROC analyses reached 0.950. Excellent separation between CLL patients and controls can be reached by using only three of several strongly affected miRNAs, miRNA-195, miRNA-29a, and miRNA-222, in CLL patients; the AUC value reached 0.982. Moreover in LLC patients there was a significant increase in the levels of miRNA-150 in ZAP-70, plasma samples. The level of miRNA-150 increased with the severity of the diseases in ZAP-70 - samples, so there is staging information associated with this marker. They also determined that the level of circulating miRNA-20a correlates reliably with diagnosis-to-treatment time. Network analysis of their data, suggests a regulatory network associated with BCL2 and ZAP-70 expression in CLL (179). 
However, we have to bear in mind that because miRNAs are exported from cells under some circumstances (18) the changes of the most abundant plasma miRNA species from miRNA-223 to miRNA-150 may be the result of the changing composition of lymphoid cells in circulation. Bone marrow stromal cells also provide key influences and protection for CLL B cells, which suggests they may play a role in producing circulating miRNAs in B CLL patients. MiRNA-451, miRNA-135a*, and miRNA486-5p are more abundant in plasma (compared with B cells), which suggests that a significant fraction of these miRNAs in circulation were released by other cell types, perhaps including bone marrow stromal cells (180).

Acute leukemia, myelodysplastic syndrome, and multiple myeloma. Leukemia cells can carry a small subset of poorlydifferentiated cells, which are considered to be precursors of lymphoblasts, myeloblasts, or monoblasts. Thus these cells are also called leukemia stem cells (LSCs) because they are capable of maintaining and propagating leukemia in vivo, while retaining the ability to differentiate into committed progeny that lack these properties. Like hematopoietic stem cells (HSCs), LSCs possess the ability of self-renewal under a complex regulatory system. The recent discovery of miRNAs may shed new light on regulation of LSCs and leukemogenesis. As master gene regulators, cellular and circulating miRNAs participate in these processes through coordinated work with key transcription factors required for hematopoiesis. Therefore, miRNAs could play a critical role in normal HSCs as well as LSCs, and in the onset of diseases such as acute leukemia and myelodysplastic syndrome (181). Cellular miRNAs are in fact of great importance in pathogenesis, diagnosis and prognosis of acute leukemia (AL). Zhu et al studied five AL-related miRNAs to confirm the significance of these miRNAs in AL. Samples tested included acute myeloid leukemia (AML) and acute lymphoblastic leukemia (ALL). Analysis showed that miRNA-128 expression was significantly higher in ALL. However, the let-7b and miRNA-223 expressions in ALL were significantly lower than in AML. Compared with normal controls, miR-128 expression was significantly higher in ALL, but there was no significant difference in AML. The expressions of Let-7b and miRNA-223 in AL group were higher than in normal controls. MiRNA-181a was quantitatively detected in AML patients, and they found that the expression of miRNA-181a in M1 or M2 patients was significantly higher compared with it in M4 or M5. It was found that the expression of miRNA-181a in favorable prognosis group was significantly lower than in poor prognosis group. In FLT3-ITD mutation positive patients, the miRNA-155 expression was significantly higher than in the negative group (182). At this time only few studies have been performed on circulating miRNA in AL, but a recent study found that plasma levels of miRNA-92 might be a biomarker for acute myeloid leukemia (183).

Two miRNAs, let-7a and miR-16, are known to play important roles in myeloid leukemogenesis by regulating the cell cycle and apoptosis, both of which are important in myelodysplastic syndrome (MDS) pathogenesis (70,184-186). Let-7a is a tumor suppressor gene that regulates oncogenes such as RAS and HMGA2, and miR-16 targets multiple oncogenes, including BCL2, MCL1, CCND1, and WNT3A. Decreased miR-16 expression also has been found in blasts isolated from high-risk MDS patients $(187,188)$. Zuo et al examined plasma levels of let-7a and miR-16, in patients with MDS and healthy persons using quantitative real-time PCR. Circulating levels of both miRNAs were similar among healthy controls but were significantly lower in MDS patients. The distributions of these miRNA levels were bimodal in MDS patients, and these levels were significantly associated with their progression-free survival and overall survival. This association persisted even after patients were stratified according to the International Prognostic Scoring System. Multivariate analysis revealed that let-7a level was a strong independent predictor for overall survival in this patient cohort. These findings suggest that let-7a and miR-16 plasma levels can serve as non-invasive prognostic markers in MDS patients (189).

Finally, Huang et al evaluated global miRNA expression profiles in the plasma of multiple myeloma (MM) patients and healthy controls. Six miRNAs (miRNA-148a, miRNA-181a, miRNA-20a, miRNA-221, miRNA-625, and miRNA-99b) that were significantly up-regulated in MM were selected and further quantified independently by quantitative reverse transcription PCR in plasma from MM patients and healthy controls. Moreover, within the patient group, the expression levels of miRNA-99b and miRNA-221 were associated with chromosomal abnormalities $\mathrm{t}(4 ; 14)$ and $\operatorname{del}(13 \mathrm{q})$, respectively. High levels of miRNA-20a and miRNA-148a were related to shorter relapse-free survival (190).

\section{Limits and challenges of circulating miRNAs}

Conventional strategies for blood-based biomarker discovery have shown promise, but their clinical use has been limited due to lack of sufficient sensitivity, specificity, and stability. New approaches that can complement and improve on current strategies for cancer detection are needed. Circulating miRNAs have immense potential for refinement of the current processes for diagnosis, staging and prognostic prediction, and they may also provide potential future therapeutic targets in the management of diseases (191). However, many challenges regarding miRNAs in sera need to be confronted. Firstly, the specificity of miRNAs: one miRNA can distinguish different cancers, which have the same serum miRNA, e.g., miR-21 in DLBCL and pancreatic cancer. Secondly, the standardization of miRNAs: the preparation of serum/plasma will need be standardized in order to generalize findings from different patients, groups, or labs. Thirdly, the quantification of miRNAs: what will be used as a standard for qRT-PCR for measuring circulating miRNAs (e.g., as 'housekeeping' serum miRNA/small RNA), as other classes of RNAs or mRNAs are not stable in serum? Moreover, the origin of miRNAs is unclear and lacks experimental evidence, but current assumptions of the origin include cancer cells in peripheral blood $(16)$ or tumor-associated bodies $(38,106)$.

Duttagupta et al found considerable proportions of miRNAs derived from red and white blood cells, present as contaminants in plasma preparations with the potential to mask the intensities of truly circulating miRNA species (192). Pritchard et al hypothesized that blood cells may contribute significantly to circulating miRNA, and that could have important implications for interpretation of results from circulating miRNA cancer biomarker studies (193). They pointed out that a majority of miRNAs reported in the literature as circulating cancer biomarkers may originate in large part from blood cells, and 
this finding is supported by other studies in this area (194). Of 79 solid tumor circulating miRNA biomarkers reported in the literature, it was found that 58\% (47/79) are highly expressed in one or more blood cell type. Plasma levels of miRNA biomarkers expressed by myeloid and lymphoid blood cells tightly correlated with corresponding white blood cell counts. Plasma miRNA biomarkers expressed by red blood cells were significantly increased in hemolyzed specimens (20- to 30-fold plasma increase). Finally, in a patient undergoing autologous hematopoietic cell transplantation, plasma levels of myeloid- and lymphoid-expressed miRNAs tracked closely with changes in corresponding blood counts. There is evidence that blood cells are a major contributor to circulating miRNA, and that perturbations in blood cell counts and hemolysis can alter plasma miRNA biomarker levels by up to 50-fold. Given that a majority of reported circulating miRNA cancer biomarkers are highly expressed in blood cells, caution is needed in interpretation of such results as they may reflect a blood cell-based phenomenon rather than a cancer-specific origin. Stratification of circulating miRNAs based on detection in circulation and/or contaminant classes reveal an approximate loss of $66 \%$ of all detected miRNAs through the removal of cellular miRNA derived signatures. The proportion of this reduction is comparable to similar extensive overlaps seen between miRNA profiles derived from plasma micro-vesicles and peripheral blood mononuclear cells (25). A direct comparison of the 20 most common circulating miRNAs from healthy individuals over 5 different datasets reveal, that at least $75 \%(15 / 20)$ of the reported circulating miRNA species can be mapped to cellular miRNA signatures $(30,195)$.

\section{Future perspectives for circulating miRNAs}

Technological applications and novel biomarkers in the field of molecular diagnostics have never been evolving at a more rapid pace. Wang et al showed that a nanopore sensor based on the $\alpha$-haemolysin protein can selectively detect miRNAs at the single molecular level in plasma samples from lung cancer patients without the need for labels or amplification of the miRNA. The sensor, which uses a programmable oligonucleotide probe to generate a target-specific signature signal, can quantify sub-picomolar levels of cancer-associated miRNAs and can distinguish single-nucleotide differences between miRNA family members. This approach is potentially useful for quantitative miRNA detection (196). However, circulating miRNAs will find a space in several different fields of application such as transplantation, and recently Spiegel et al pointed out the role of miRNAs in immunology and transplantation medicine and their role as potential biomarkers. They also focused on the molecular mechanisms and therapeutic implications of the use of miRNA-based therapeutic strategies to improve long-term allograft survival (197).

\section{Conclusions}

The discovery of miRNA in general and particularly of circulating miRNA is one of the major scientific breakthroughs in recent years and has revolutionized current cell biology and medical science. Therapeutic strategies based on modulation of miRNA activity hold great promise due to the ability of these small RNAs to significantly alter cellular behavior. MiRNAs function as 'extracellular communication RNAs' that play an important role in cell proliferation and differentiation $(23,198)$. A more comprehensive study of circulating miRNAs and their association with various physiopathological conditions may lead to another dimension in the discovery of biomarkers in the blood for many physiological and pathological conditions. As circulating miRNAs regulate the expression of multiple genes in a disease pathway, circulating miRNAs and the genes they influence can be therapeutic targets. Currently, there are clinical trials evaluating therapy based on miRNA inhibition or overexpression. For instance overexpression and down-regulation of specific miRNAs are being evaluated as a novel approach to the treatment of myocardial infarction (199).

Within a few years, we will know if miRNA-based therapeutics, alone or in combination with other modalities, will be clinically useful treatments for various diseases (200). Then it could be that blood-based circulating miRNA analysis has imminent clinical utility as disease markers. However, if this concept is to translate readily from bench to bedside, then supporting data demonstrating validity of this novel approach must stem from carefully planned studies. If the current momentum in translational research can be maintained, then an era of non-invasive rapid diagnostics is rapidly forthcoming.

\section{Acknowledgements}

We would like to thank Ms. Vivian De la Cruz for reading the manuscript.

\section{References}

1. Setoyama T, Ling $\mathrm{H}$, Natsugoe $\mathrm{S}$ and Calin GA: Non-coding RNAs for medical practice in oncology. Keio J Med 60: 106-113, 2011.

2. Carninci P, Kasukawa T, Katayama S, et al: The transcriptional landscape of the mammalian genome. Science 309: 1559-1563, 2005.

3. Kapranov P, Drenkow J, Cheng J, Long J, Helt G, Dike S and Gingeras TR: Examples of the complex architecture of the human transcriptome revealed by RACE and high-density tiling arrays. Genome Res 15: 987-997, 2005.

4. Mercer TR, Dinger ME and Mattick JS: Long non-coding RNAs: insights into functions. Nat Rev Genet 10: 155-159, 2009.

5. Taft RJ, Pang KC, Mercer TR, Dinger M and Mattick JS: Noncoding RNAs: regulators of disease. J Pathol 220: 126-139, 2010.

6. Gupta RA, Shah N, Wang KC, et al: Long non-coding RNA HOTAIR reprograms chromatin state to promote cancer metastasis. Nature 464: 1071-1076, 2010

7. Friedman RC, Farh KK, Burge CB and Bartel DP: Most mammalian mRNAs are conserved targets of microRNAs. Genome Res 19: 92-105, 2009.

8. Lee RC,Feinbaum RL and Ambros V: The C.elegans heterochronic gene lin-4 encodes small RNAs with antisense complementarity to lin-14. Cell 75: 843-854, 1993.

9. Bartel DP and Chen CZ: Micromanagers of gene expression: the potentially widespread influence of metazoan microRNAs. Nat Rev Genet 5: 396-400, 2004.

10. Zhao T, Li G, Mi S, Li S, Hannon GJ, Wang XJ and Qi Y: A complex system of small RNAs in the unicellular green alga Chlamydomonas reinhardtii. Genes Dev 21: 1190-1203, 2007.

11. Lee Y, Kim M, Han J, Yeom KH, Lee S, Baek SH and Kim VN: MicroRNA genes are transcribed by RNA polymerase II. EMBO J 23: 4051-4060, 2004.

12. Borchert GM, Lanier W and Davidson BL: RNA polymerase III transcribes human microRNAs. Nat Struct Mol Biol 13: 1097-1101, 2006.

13. Hu HY, Yan Z, Xu Y, et al: Sequence features associated with microRNA strand selection in humans and flies. BMC Genomics 10: 413, 2009. 
14. Fabian MR, Sonenberg N and Filipowicz W: Regulation of mRNA translation and stability by microRNAs. Annu Rev Biochem 79: 351-379, 2010.

15. Fiorucci G, Chiantore MV, Mangino G, Percario ZA, Affabris E and Romeo G: Cancer regulator microRNA: potential relevance in diagnosis, prognosis and treatment of cancer. Curr Med Chem 19: 461-474, 2012 .

16. Zen $\mathrm{K}$ and Zhang CY: Circulating microRNAs: a novel class of biomarkers to diagnose and monitor human cancers. Med Res Rev 32: 326-348, 2012.

17. Weber JA, Baxter DH, Zhang S, et al: The microRNA spectrum in 12 body fluids. Clin Chem 56: 1733-1741, 2010.

18. Wang K, Zhang S, Weber J, Baxter D and Galas DJ: Export of microRNAs and microRNA-protective protein by mammalian cells. Nucleic Acids Res 38: 7248-7259, 2010.

19. Zubakov D, Boersma AW, Choi Y, van Kuijk PF, Wiemer EA and Kayser M: MicroRNA markers for forensic body fluid identification obtained from microarray screening and quantitative RT-PCR confirmation. Int J Legal Med 124: 217-226, 2010

20. Hanson EK, Lubenow $\mathrm{H}$ and Ballantyne J: Identification of forensically relevant body fluids using a panel of differentially expressed microRNAs. Anal Biochem 387: 303-314, 2009.

21. Weickmann JL and Glitz DG: Human ribonucleases. Quantitation of pancreatic-like enzymes in serum, urine, and organ preparations. J Biol Chem 257: 8705-8710, 1982.

22. Gibbings DJ, Ciaudo C, Erhardt M and Voinnet O: Multivesicular bodies associate with components of miRNA effector complexes and modulate miRNA activity. Nat Cell Biol 11: 1143-1149,2009.

23. Valadi H,Ekstrom K, Bossios A, Sjostrand M, Lee JJ and Lotvall JO Exosome-mediated transfer of mRNAs and microRNAs is a novel mechanism of genetic exchange between cells. Nat Cell Biol 9: 654-659, 2007

24. Iguchi $\mathrm{H}$, Kosaka $\mathrm{N}$ and Ochiya T: Secretory microRNAs as a versatile communication tool. Commun Integr Biol 3: 478-481, 2010.

25. Camussi G, Deregibus MC, Bruno S, Cantaluppi V and Biancone L: Exosomes/microvesicles as a mechanism of cell-to-cell communication. Kidney Int 78: 838-848, 2010.

26. Muralidharan-Chari V, Clancy JW, Sedgwick A and D'SouzaSchorey C: Microvesicles: mediators of extracellularcommunication during cancer progression. J Cell Sci 123: 1603-1611, 2010.

27. Cortez MA, Bueso-Ramos C, Ferdin J, Lopez-Berestein G, Sood AK and Calin GA: MicroRNAs in body fluids - the mix of hormones and biomarkers. Nat Rev Clin Oncol 8: 467-477, 2011.

28. Etheridge A, Lee I, Hood L, Galas D and Wang K: Extracellular microRNA: a new source of biomarkers. Mutat Res 717: 85-90, 2011.

29. Skog J, Wurdinger T, van Rijn S, et al: Glioblastoma microvesicles transport RNA and proteins that promote tumour growth and provide diagnostic biomarkers. Nat Cell Biol 10: 1470-1476, 2008

30. Hunter MP, Ismail N, Zhang X, et al: Detection of microRNA expression in human peripheral blood microvesicles. PLoS One 3: e3694, 2008.

31. Michael A, Bajracharya SD, Yuen PS, Zhou H, Star RA, Illei GG and Alevizos I: Exosomes from human saliva as a source of microRNA biomarkers. Oral Dis 16: 34-38, 2010.

32. Dimov I, Velickovic L and Stefanovic V: Urinary exosomes. Sci World J 9: 1107-1118, 2009.

33. Blanchard N, Lankar D, Faure F, Regnault A, Dumont C, Raposo G and Hivroz C: TCR activation of human T cells induces the production of exosomes bearing the TCR/CD3/zeta complex. J Immunol 168: 3235-3241, 2002.

34. Raposo G, Nijman HW, Stoorvogel W, Liejendekker R, Harding CV, Melief CJ and Geuze HJ: B lymphocytes secrete antigen-presenting vesicles. J Exp Med 183: 1161-1172, 1996.

35. Thery C, Regnault A, Garin J, et al: Molecular characterization of dendritic cell-derived exosomes. Selective accumulation of the heat shock protein hsc73. J Cell Biol 147: 599-610, 1999.

36. Mears R, Craven RA, Hanrahan S, et al: Proteomic analysis of melanoma-derived exosomes by two-dimensional polyacrylamide gel electrophoresis and mass spectrometry. Proteomics 4 : 4019-4031, 2004.

37. O'Neill HC and Quah BJ: Exosomes secreted by bacterially infected macrophages are proinflammatory. Sci Signal 1: 8 2008.

38. Taylor DD and Gercel-Taylor C: MicroRNA signatures of tumorderived exosomes as diagnostic biomarkers of ovarian cancer Gynecol Oncol 110: 13-21, 2008.

39. Denzer K, Kleijmeer MJ, Heijnen HF, Stoorvogel W and Geuze HJ: Exosome: from internal vesicle of the multivesicular body to intercellular signaling device. J Cell Sci 113: 3365-3374, 2000.
40. Huber V, Filipazzi P, Iero M, Fais S and Rivoltini L: More insights into the immunosuppressive potential of tumor exosomes. J Transl Med 6: 63, 2008.

41. Xiang X, Poliakov A, Liu C, et al: Induction of myeloid-derived suppressor cells by tumor exosomes. Int J Cancer 124: 2621-2633, 2009.

42. Vallhov H, Gutzeit C, Johansson SM, et al: Exosomes containing glycoprotein 350 released by EBV-transformed B cells selectively target B cells through CD21 and block EBV infection in vitro. J Immunol 186: 73-82, 2011.

43. Shen J, Todd NW, Zhang H, et al: Plasma microRNAs as potential biomarkers for non-small-cell lung cancer. Lab Invest 91: 579-587, 2011.

44. Mitchell PS, Parkin RK, Kroh EM, et al: Circulating microRNAs as stable blood-based markers for cancer detection. Proc Natl Acad Sci USA 105: 10513-10518, 2008.

45. Gilad S, Meiri E, Yogev Y, et al: Serum microRNAs are promising novel biomarkers. PLoS One 3: e3148, 2008

46. Kosaka N, Iguchi H, Yoshioka Y, Takeshita F, Matsuki Y and Ochiya T: Secretory mechanisms and intercellular transfer of microRNAs in living cells. J Biol Chem 285: 17442-17452, 2010.

47. Turchinovich A, Weiz L, Langheinz A and Burwinkel B: Characterization of extracellular circulating microRNA. Nucleic Acids Res 39: 7223-7233, 2011

48. Chen X, Ba Y, Ma L, et al: Characterization of microRNAs in serum: a novel class of biomarkers for diagnosis of cancer and other diseases. Cell Res 18: 997-1006, 2008.

49. Li J, Smyth P, Flavin R, et al: Comparison of miRNA expression patterns using total RNA extracted from matched samples of formalin-fixed paraffin-embedded (FFPE) cells and snap-frozen cells. BMC Biotechnol 7: 36, 2007.

50. Xie Y, Todd NW, Liu Z, Zhan M and Fang H: Altered miRNA expression in sputum for diagnosis of non-small cell lung cancer. Lung Cancer 67: 170-176, 2010.

51. Tsujiura M,Ichikawa D, Komatsu S, et al: Circulating microRNAs in plasma of patients with gastric cancers. Br J Cancer 102: 1174-1179, 2010.

52. Huang Z, Huang D, Ni S, Peng Z, Sheng W and Du X: Plasma microRNAs are promising novel biomarkers for early detection of colorectal cancer. Int J Cancer 127: 118-126, 2010

53. Xi Y,Nakajima G, Gavin E, et al: Systematic analysis of microRNA expression of RNA extracted from fresh frozen and formalin-fixed paraffin-embedded samples. RNA 13: 1668-1674, 2007.

54. Schöler N, Langer C and Kuchenbauer F: Circulating microRNAs as biomarkers - true blood? Genome Med 3: 72, 2011.

55. Wang G, Tam LS, Li EK, et al: Serum and urinary free microRNA level in patients with systemic lupus erythematosus. Lupus 20: 493-500, 2011.

56. Shaoqing Y, Ruxin Z, Guojun L, Zhiqiang Y, Hua H, Shudong Y and Jie Z: Microarray analysis of differentially expressed microRNAs in allergic rhinitis. Am J Rhinol Allergy 25: 242-246, 2011.

57. Zahm AM, Thayu M, Hand NJ, Horner A, Leonard MB and Friedman JR: Circulating microRNA is a biomarker of pediatric Crohn disease. J Pediatr Gastroenterol Nutr 53: 26-33, 2011

58. Wu F, Guo NJ, Tian H, et al: Peripheral blood microRNAs distinguish active ulcerative colitis and Crohn's disease. Inflamm Bowel Dis 17: 241-250, 2011.

59. Zampetaki A, Kiechl S, Drozdov I, et al: Plasma microRNA profiling reveals loss of endothelial miR-126 and other microRNAs in type 2 diabetes. Circ Res 107: 810-817, 2010.

60. Karolina DS, Armugam A, Tavintharan S, Wong MTK, Lim SC, Sum CF and Jeyase K: MicroRNA 144 impairs insulin signaling by inhibiting the expression of insulin receptor substrate 1 in type 2 diabetes mellitus. PLos One 6: e22839, 2011.

61. Cogswell JP, Ward J, Taylor IA, et al: Identification of miRNA changes in Alzheimer's disease brain and CSF yields putative biomarkers and insights into disease pathways. J Alzheimers Dis 14: $27-41,2008$.

62. Geekiyanage H, Jicha GA, Nelson PT and Chan C: Blood serum miRNA: non-invasive biomarkers for Alzheimer's disease. Exp Neurol 235: 491-496, 2012.

63. Beveridge NJ and Cairns MJ: MicroRNA dysregulation in schizophrenia. Neurobiol Dis 46: 263-271, 2012.

64. Mizuno H, Nakamura A, Aoki Y, et al: Identification of musclespecific microRNAs in serum of muscular dystrophy animal models: promising novel blood-based markers for muscular dystrophy. PLoS One 6: e18388, 2011.

65. Laterza OF, Lim L, Garrett-Engele PW, et al: Plasma microRNAs as sensitive and specific biomarkers of tissue injury. Clin Chem 55: 1977-1983, 2009. 
66. Xu J, Zhao J, Evan G, Xiao C, Cheng Y and Xiao J: Circulating microRNAs: novel biomarkers for cardiovascular diseases. J Mol Med (Berl) 90: 865-875, 2012.

67. Li H, Guo L, Wu Q, Lu J, Ge Q and Lu Z: A comprehensive survey of maternal plasma miRNAs expression profiles using highthroughput sequencing. Clin Chim Acta 413: 568-576, 2012.

68. Chim SS, Shing TK, Hung EC, et al: Detection and characterization of placental microRNAs in maternal plasma. Clin Chem 54: 482-490, 2008

69. Gunel T, Zeybek YG, Akçakaya P, Kalelioğlu I, Benian A, Ermis H and Aydinli K: Serum microRNA expression in pregnancies with preeclampsia. Genet Mol Res 10: 4034-4040, 2011.

70. Calin GA, Sevignani C, Dumitru CD, et al: Human microRNA genes are frequently located at fragile sites and genomic regions involved in cancers. Proc Natl Acad Sci USA 101: 2999-3004, 2004.

71. Asaga S, Kuo C, Nguyen T, Terpenning M, Giuliano AE and Hoon DS: Direct serum assay for microRNA-21 concentrations in early and advanced breast cancer. Clin Chem 57: 84-91, 2011.

72. Cho WC: MicroRNAs in cancer-from research to therapy. Biochim Biophys Acta 1805: 209-217, 2010.

73. Cho WC: MicroRNAs: potential biomarkers for cancer diagnosis, prognosis and targets for therapy. Int J Biochem Cell Biol 42: $1273-1281,2010$

74. Lu J, Getz G, Miska EA, et al: MicroRNA expression profiles classify human cancers. Nature 435: 834-838, 2005.

75. Chan JA, Krichevsky AM and Kosik KS: MicroRNA-21 is an antiapoptotic factor in human glioblastoma cells. Cancer Res 65 6029-6033, 2005.

76. Iorio MV,Ferracin M, Liu CG, et al: MicroRNA gene expression deregulation in human breast cancer. Cancer Res 65: 7065-7070, 2005 .

77. Markou A, Tsaroucha EG, Kaklamanis L, et al: Prognostic value of mature microRNA-21 and microRNA-205 overexpression in nonsmall cell lung cancer by quantitative real-time RT-PCR Clin Chem 54: 1696-1704, 2008.

78. Schetter AJ, Leung SY, Sohn JJ, et al: MicroRNA expression profiles associated with prognosis and therapeutic outcome in colon adenocarcinoma. JAMA 299: 425-436, 2008.

79. Huang YS, Dai Y, Yu XF, et al: Microarray analysis of microRNA expression in hepatocellular carcinoma and non-tumorous tissues without viral hepatitis. J Gastroenterol Hepatol 23: 87-94, 2008.

80. Ladeiro Y, Couchy G, Balabaud C, et al: MicroRNA profiling in hepatocellular tumors is associated with clinical features and oncogene/tumor suppressor gene mutations. Hepatology 47 : 1955-1963, 2008

81. Bandrés E, Cubedo E, Agirre X, et al: Identification by real-time PCR of 13 mature microRNAs differentially expressed in colorectal cancer and non-tumoral tissues. Mol Cancer 5: 29, 2006.

82. Slaby O, Svoboda M, Fabian P, et al: Altered expression of miR-21, miR-31, miR-143 and miR-145 is related to clinicopathologic features of colorectal cancer. Oncology 72: 397-402, 2007.

83. Motoyama K, Inoube H, Takatsuno Y, et al: Over- and underexpressed microRNAs in human colorectal cancer. Int J Oncol 34: 1069-1075, 2009

84. Wang CJ, Zhou ZG, Wang L, et al: Clinicopathological significance of microRNA-31,-143 and -145 expression in colorecta cancer. Dis Markers 26: 27-34, 2009.

85. Yan LIX, Huang XF, Shao Q, et al: MicroRNA miR-21 overexpression in human breast cancer is associated with advanced clinical stage, lymph node metastasis and patient poor prognosis. RNA 14: 2348-2360, 2008.

86. Valastyan S, Reinhardt F, Benaich N, et al: A pleiotropically acting microRNA, miR-31, inhibits breast cancer metastasis. Cell 137: 1032-1046, 2009

87. Guo J, Miao Y, Xiao B, et al: Differential expression of microRNA species in human gastric cancer versus non-tumorous tissues. J Gastroenterol Hepatol 24: 652-657, 2009.

88. Veerla S, Lindgren D, Kvist A, et al: MiRNA expression in urothelial carcinomas: important roles of miR-10a, miR-222, miR-125b, miR-7 and miR-452 for tumor stage and metastasis, and frequent homozygous losses of miR-31. Int J Cancer 124: 2236-2242, 2009.

89. Rosenfeld N, Aharonov R, Meiri E, et al: MicroRNAs accurately identify cancer tissue origin. Nat Biotechnol 26: 462-469, 2008.

90. He JF, Luo YM, Wan XH and Jiang D: Biogenesis of miRNA-195 and its role in biogenesis, the cell cycle, and apoptosis. J Biochem Mol Toxicol 25: 404-408, 2011.

91. Donzelli S, Fontemaggi G, Fazi F, et al: MicroRNA-128-2 targets the transcriptional repressor E2F5 enhancing mutant p53 gain of function. Cell Death Differ 19: 1038-1048, 2012.
92. Yin R, Bao W, Xing Y, Xi T and Gou S: MiR-19b-1 inhibits angiogenesis by blocking cell cycle progression of endothelial cells. Biochem Biophys Res Commun 417: 771-776, 2012.

93. Enkelmann A, Heinzelmann J, von Eggeling F, et al: Specific protein and miRNA patterns characterise tumour-associated fibroblasts in bladder cancer. J Cancer Res Clin Oncol 137 : 751-759, 2011

94. Schaar DG, Medina DJ, Moore DF, Strair RK and Ting YI miR-320 targets transferrin receptor 1 (CD71) and inhibits cell proliferation. Exp Hematol 37: 245-255, 2009.

95. Ichimi T, Enokida H, Okuno Y, et al: Identification of nove microRNA targets based on microRNA signatures in bladder cancer. Int J Cancer 125: 345-352, 2009.

96. Chiyomaru T, Enokida H, Tatarano S, et al: miR-145 and miR-133a function as tumour suppressors and directly regulate FSCN1 expression in bladder cancer. Br J Cancer 102: 883-891, 2010.

97. Ostenfeld MS, Bramsen JB, Lamy P, et al: miR-145 induces caspase-dependent and -independent cell death in urothelial cancer cell lines with targeting of an expression signature present in Ta bladder tumors. Oncogene 29: 1073-1084, 2010.

98. Aprelikova O, Yu X, Palla J, et al: The role of miR-31 and its target gene SATB2 in cancer-associated fibroblasts. Cell Cycle 9: 4387-4398, 2010.

99. Rana TM: Illuminating the silence: understanding the structure and function of small RNAs. Nat Rev Mol Cell Biol 8: 23-36, 2007.

100. Bullock MD, Sayan AE, Packham GK and Mirnezami AH microRNAs: critical regulators of epithelial to mesenchymal (EMT) and mesenchymal to epithelial transition (MET) in cancer progression. Biol Cell 104: 3-12, 2012.

101. Avila-Moreno F, Urrea F and Ortiz-Quintero B: MicroRNAs in diagnosis and prognosis in lung cancer. Rev Invest Clin 63 516-535, 2011

102. Segura MF, Belitskaya-Lévy I, Rose AE, et al: Melanoma microRNA signature predicts post-recurrence survival. Clin Cancer Res 16: 1577-1586, 2010.

103. Yu SL, Chen HY, Chang GC, et al: MicroRNA signature predicts survival and relapse in lung cancer. Cancer Cell 13: 48-57, 2008

104. Zhou N and Mo YY: Roles of microRNAs in cancer stem cells Front Biosci 4: 810-818, 2012

105. Ho AS, Huang X, Cao H, et al: Circulating miR-210 as a novel hypoxia marker in pancreatic cancer. Transl Oncol 3: 109-113, 2010.

106. Resnick KE, Alder H, Hagan JP, et al: The detection of differentially expressed microRNAs from the serum of ovarian cancer patients using a novel real-time PCR platform. Gynecol Oncol 112: 55-59, 2009.

107. Ng EK, Chong WW, Jin H, et al: Differential expression of microRNAs in plasma of patients with colorectal cancer: a potentialmarkerforcolorectalcancerscreening.Gut58:1375-1381, 2009.

108. Wentz-Hunter KK and Potashkin JA: The role of miRNAs as key regulators in the neoplastic microenvironment. Mol Biol Int 2011: 839872, 2011

109. Kosaka N, Iguchi $\mathrm{H}$ and Ochiya T: Circulating microRNA in body fluid: a new potential biomarker for cancer diagnosis and prognosis. Cancer Sci 101: 2087-2092, 2010

110. Roth C,Rack B,Muller V,Janni W,PantelK and Schwarzenbach H: Circulating microRNAs as blood-based markers for patients with primary and metastatic breast cancer. Breast Cancer Res 12: R90, 2010.

111. Yu L, Todd NW, Xing L, Xie Y, Zhang H, Liu Z and Jiang F: Early detection of lung adenocarcinoma in sputum by a panel of microRNA markers. Int J Cancer 127: 2870-2878, 2010.

112. Xing L, Todd NW, Yu L, Fang H and Jiang F: Early detection of squamous cell lung cancer in sputum by a panel of microRNA markers. Mod Pathol 8: 1157-1164, 2010.

113. Pezzolesi MG, Platzer P, Waite KA and Eng C: Differential expression of PTEN-targeting microRNAs miR-19a and miR-21 in Cowden syndrome. Am J Hum Genet 82: 1141-1149, 2008

114. Zhu S, Si ML, Wu H and Mo YY: MicroRNA-21 targets the tumor suppressor gene tropomyosin 1 (TPM1). J Biol Chem 282 14328-14336, 2007

115. Du Rieu MC, Torrisani J, Selves J, et al: MicroRNA-21 is induced early in pancreatic ductal adenocarcinoma precursor lesions. Clin Chem 56: 603-612, 2010.

116. Zhang HL, Yang LF, Zhu Y, et al: Serum miRNA-21: elevated levels in patients with metastatic hormone-refractory prostate cancer and potential predictive factor for the efficacy of docetaxelbased chemotherapy. Prostate 71: 326-331, 2011. 
117. Shen J, Liu Z, Todd NW, et al: Diagnosis of lung cancer in individuals with solitary pulmonary nodules by plasma microRNA biomarkers. BMC Cancer 11: 374, 2011.

118. Wei J, Gao W, Zhu CJ, Liu YQ, Mei Z, Cheng T and Shu YQ: Identification of plasma micro-RNA-21 as a biomarker for early detection and chemosensitivity of non-small cell lung cancer. Chin J Cancer 30: 407-414, 2011.

119. Oh HK, Tan AL, Das K, et al: Genomic loss of miR-486 regulates tumor progression and the OLFM4 anti-apoptotic factor in gastric cancer. Clin Cancer Res 17: 2657-2667, 2011.

120. Mees ST, Mardin WA, Sielker S, et al: Involvement of CD40 targeting miR-224 and miR-486 on the progression of pancreatic ductal adenocarcinomas. Ann Surg Oncol 16: 2339-2350, 2009.

121. Bansal A, Lee IH, Hong X, et al: Feasibility of microRNAs as biomarkers for Barrett's esophagus progression: a pilot crosssectional, phase 2 biomarker study. Am J Gastroenterol 106: 1055-1063, 2011

122. Huang X, Ding L, Bennewith KL, et al: Hypoxia-inducible mir-210 regulates normoxic gene expression involved in tumo initiation. Mol Cell 35: 856-867, 2009.

123. Roth C, Kasimir-Bauer S, Pantel K and Schwarzenbach $\mathrm{H}$ Screening for circulating nucleic acids and caspase activity in the peripheral blood as potential diagnostic tools in lung cancer Mol Oncol 5: 281-291, 2011

124.Zheng D, Haddadin S, Wang Y, Gu LQ, Perry MC, Freter CE and Wang MX: Plasma microRNAs as novel biomarkers for early detection of lung cancer. Int J Clin Exp Pathol 4: 575-586, 2011

125. Heegaard NH, Schetter AJ, Welsh JA, Yoneda M, Bowman ED and Harris CC: Circulating microRNA expression profiles in early stage non-small cell lung cancer. Int J Cancer 130: 1378-1386, 2012

126. Bianchi F, Nicassio F, Marzi M, et al: A serum circulating miRNA diagnostic test to identify asymptomatic high-risk individuals with early stage lung cancer. EMBO Mol Med 3: 495-503, 2011.

127. Bockmeyer CL, Christgen M, Müller M, et al: MicroRNA profiles of healthy basal and luminal mammary epithelial cells are distinct and reflected in different breast cancer subtypes. Breast Cancer Res Treat 130: 735-745, 2011

128. Blenkiron C, Goldstein LD, Thorne NP, et al: MicroRNA expression profiling of human breast cancer identifies new markers of tumor subtype. Genome Biol 8: 214, 2007.

129. Adams BD, Guttilla IK and White BA: Involvement of microRNAs in breast cancer. Semin Reprod Med 26: 522-536, 2008.

130. Enerly E, Steinfeld I, Kleivi K, et al: miRNA-mRNA integrated analysis reveals roles for miRNAs in primary breast tumors. PLoS One 6: e16915, 2011.

131. Yu F, Yao H, Zhu P, et al: let-7 regulates self renewal and tumorigenicity of breast cancer cells. Cell 131: 1109-1123, 2007.

132. Tavazoie SF, Alarcón C, Oskarsson T, et al: Endogenous human microRNAs that suppress breast cancer metastasis. Nature 451: $147-152,2008$

133. Hurteau GJ, Carlson JA, Spivack SD and Brock GJ: Overexpression of the microRNA hsa-miR-200c leads to reduced expression of transcription factor 8 and increased expression of E-cadherin Cancer Res 67: 7972-7976, 2007.

134. Bertos NR and Park M: Breast cancer - one term, many entities? J Clin Invest 121: 3789-3796, 2011.

135. Heneghan HM, Miller N and Kerin MJ: Circulating microRNAs: promising breast cancer. Breast Cancer Res 13: 402, 2011

136. Ratajczak J, Wysoczynski M, Hayek F, Janowska-Wieczorek A and Ratajczak MZ: Membrane-derived microvesicles: important and underappreciated mediators of cell-to-cell communication. Leukemia 20: 1487-1495, 2006.

137. Ohshima K, Inoue K, Fujiwara A, et al: Let-7 microRNA family is selectively secreted into the extracellular environment via exosomes in a metastatic gastric cancer cell line. PLoS One 5: e13247, 2010

138. Gourzones C, Gelin A, Bombik I, et al: Extra-cellular release and blood diffusion of BART viral micro-RNAs produced by EBV-infected nasopharyngeal carcinoma cells. Virol J 7: 271 , 2010

139. Luo SS, Ishibashi O, Ishikawa G, et al: Human villous trophoblasts express and secrete placenta-specific microRNAs into maternal circulation via exosomes. Biol Reprod 81: 717-729, 2009.

140. Yang M, Chen J, Su F, et al: Microvesicles secreted by macrophages shuttle invasion-potentiating microRNAs into breast cancer cells. Mol Cancer 10: 117, 2011.
141. Sarasin-Filipowicz M, Krol J, Markiewicz I, Heim MH and Filipowicz W: Decreased levels of microRNA miR-122 in individuals with hepatitis $C$ responding poorly to interferon therapy. Nat Med 15: 31-33, 2009

142. Morita K, Taketomi A, Shirabe K, et al: Clinical significance and potential of hepatic microRNA-122 expression in hepatitis $\mathrm{C}$. Liver Int 31: 474-484, 2011.

143. Wang K, Zhang S, Marzolf B, et al: Circulating microRNAs, potential biomarkers for drug-induced liver injury. Proc Natl Acad Sci USA 106: 4402-4407, 2009

144. Zhang Y, Jia Y, Zheng R, et al: Plasma microRNA-122 as a biomarker for viral-, alcohol-, and chemical-related hepatic diseases. Clin Chem 56: 1830-1838, 2010.

145. Xu J, Wu C, Che X, et al: Circulating microRNAs, miR-21, miR-122, and miR-223, in patients with hepatocellular carcinoma or chronic hepatitis. Mol Carcinog 50: 136-142, 2011.

146. Tomimaru Y, Eguchi H, Nagano H, et al: Circulating microRNA-21 as a novel biomarker for hepatocellular carcinoma. J Hepatol 56: 167-175, 2012.

147. Cermelli S, Ruggieri A, Marrero JA, Ioannou GN and Beretta L: Circulating microRNAs in patients with chronic hepatitis $\mathrm{C}$ and non-alcoholic fatty liver disease. PLoS One 6: e23937, 2011.

148. Qi P, Cheng SQ, Wang H, Li N, Chen YF and Gao CF: Serum microRNAs as biomarkers for hepatocellular carcinoma in Chinese patients with chronic hepatitis B virus infection. PLoS One 6: e28486, 2011.

149. Ikeda Y, Tanji E, Makino N, Kawata S and Furukawa T: MicroRNAs associated with mitogen-activated protein kinase in human pancreatic cancer. Mol Cancer Res 10: 259-269, 2012.

150. Habbe N, Koorstra J, Mendell J, et al: MicroRNA miR-155 is a biomarker of early pancreatic neoplasia. Cancer Biol Ther 8 : 340-346, 2009.

151. La Conti JL, Shivapurkar N, Preet A, et al: Tissue and serum microRNAs in the KrasG12D transgenic animal model and in patients with pancreatic cancer. PLoS One 6: e20687, 2011.

152. Morimura R, Komatsu S, Ichikawa D, et al: Novel diagnostic value of circulating miR-18a in plasma of patients with pancreatic cancer. Br J Cancer 105: 1733-1740, 2011.

153. Liu R, Chen X, Du Y, et al: Serum microRNA expression profile as a biomarker in the diagnosis and prognosis of pancreatic cancer. Clin Chem 58: 610-618, 2012

154. Hwang JH, Voortman J, Giovannetti E, et al: Identification of microRNA-21 as a biomarker for chemoresistance and clinical outcome following adjuvant therapy in resectable pancreatic cancer. PLoS One 5: e10630, 2010.

155. Shigehara K, Yokomuro S, Ishibashi O, et al: Real-time PCR-based analysis of the human bile microRNAome identifies miR-9 as a potential diagnostic biomarker for biliary tract cancer. PLoS One 6: e23584, 2011

156. Komatsu S, Ichikawa D, Takeshita $\mathrm{H}$, et al: Circulating microRNAs in plasma of patients with oesophageal squamous cell carcinoma. Br J Cancer 105: 104-111, 2011.

157. Chiang Y,Zhou X, Wang Z, et al: Expression levels of microRNA192 and -215 in gastric carcinoma. Pathol Oncol Res 18: 585-591, 2012.

158. Wang J,Zhang J, Wu J, et al: MicroRNA-610 inhibits the migration and invasion of gastric cancer cells by suppressing the expression of vasodilator-stimulated phosphoprotein. Eur J Cancer [Epub ahead of print] 2011

159. Liu H, Zhu L, Liu B, et al: Genome-wide microRNA profiles identify miR-378 as a serum biomarker for early detection of gastric cancer. Cancer Lett 316: 196-203, 2012.

160. Wu J, Wu G, Lv L, et al: MicroRNA-34a inhibits migration and invasion of colon cancer cells via targeting to Fra-1. Carcinogenesis 33: 519-528, 2012

161. Nugent M, Miller N and Kerin MJ: MicroRNAs in colorectal cancer: function, dysregulation and potential as novel biomarkers. Eur J Surg Oncol 37: 649-654, 2011.

162. Cheng H, Zhang L, Cogdell DE, et al: Circulating plasma MiR-141 is a novel biomarker for metastatic colon cancer and predicts poor prognosis. PLoS One 6: e17745, 2011.

163. Wulfken LM, Moritz R, Ohlmann C, et al: MicroRNAs in renal cell carcinoma: diagnostic implications of serum miR-1233 levels. PLoS One 6: e25787, 2011.

164. Mahn R, Heukamp LC, Rogenhofer S, von Ruecker A, Müller SC and Ellinger J: Circulating microRNAs (miRNA) in serum of patients with prostate cancer. Urology 77: 9-16, 2011

165. Lodes MJ, Caraballo M, Suciu D, Munro S, Kumar A and Anderson B: Detection of cancer with serum miRNAs on an oligonucleotide microarray. PLoS One 4: e6229, 2009. 
166. Brase JC, Johannes M, Schlomm T, et al: Circulating miRNAs are correlated with tumor progression in prostate cancer. Int $\mathrm{J}$ Cancer 128: 608-616, 2010.

167. Moltzahn F, Olshen AB, Baehner L, et al: Microfluidic-based multiplex qRT-PCR identifies diagnostic and prognostic microRNA signatures in the sera of prostate cancer patients. Cancer Res 71: 550-560, 2011.

168. Wach S, Nolte E, Szczyrba J, et al: MicroRNA profiles of prostate carcinoma detected by multiplatform microRNA screening. Int J Cancer 130: 611-621, 2012

169. Kuwabara Y, Ono K, Horie T, et al: Increased microRNA-1 and microRNA-133a levels in serum of patients with cardiovascular disease indicate the existence of myocardial damage. Circ Cardiovasc Genet 4: 446-454, 2011

170. Hanke M, Hoefig K, Merz H, et al: A robust methodology to study urine microRNA as tumor marker: microRNA-126 and microRNA-182 are related to urinary bladder cancer. Urol Oncol 28: 655-661, 2010.

171. Selth LA, Townley S, Gillis JL, et al: Discovery of circulating microRNAs associated with human prostate cancer using a mouse model of disease. Int J Cancer 131: 652-661, 2012.

172. Gonzales JC, Fink LM, Goodman OB Jr, Symanowski JT, Vogelzang NJ and Ward DC: Comparison of circulating MicroRNA 141 to circulating tumor cells, lactate dehydrogenase, and prostate-specific antigen for determining treatment response in patients with metastatic prostate cancer. Clin Genitourin Cancer 9: 39-45, 2011.

173. Lin SC, Liu CJ, Lin JA, et al: miR-24 up-regulation in ora carcinoma: positive association from clinical and in vitro analysis. Oral Oncol 46: 204-208, 2010.

174. Park NJ, Zhou H, Elashoff D, Henson BS, Kastratovic DA, Abemayor E and Wong DT: Salivary microRNA: discovery, characterization, and clinical utility for oral cancer detection. Clin Cancer Res 15: 5473-5477, 2009.

175. Lawrie CH, Gal S, Dunlop HM, et al: Detection of elevated levels of tumour-associated microRNAs in serum of patients with diffuse large B-cell lymphoma. Br J Haematol 141: 672-675, 2008.

176. Cheng AM, Byrom MW, Shelton J and Ford LP: Antisense inhibition of human miRNAs and indications for an involvement of miRNA in cell growth and apoptosis. Nucleic Acids Res 33: 1290-1297, 2005

177. Si ML, Zhu S, Wu H, Lu Z, Wu F and Mo YY: miR-21-mediated tumor growth. Oncogene 26: 2799-2803, 2006.

178. Stamatopoulos B, Meuleman N, Haibe-Kains B, et al: MicroRNA$29 \mathrm{c}$ and microRNA-223 downregulation has in vivo significance in chronic lymphocytic leukemia and improves disease risk stratification. Blood 113: 5237-5245, 2009.

179. Moussay E, Wang K, Cho JH, et al: MicroRNA as biomarkers and regulators in B-cell chronic lymphocytic leukemia. Proc Natl Acad Sci USA 108: 6573-6578, 2011.

180. Fulci V, Chiaretti S, Goldoni M, et al: Quantitative technologies establish a novel microRNA profile of chronic lymphocytic leukemia. Blood 109: 4944-4951, 2007.

181. Huang $\mathbf{J}$ and Mo YY: Role of microRNAs in leukemia stem cells. Front Biosci (Schol Ed) 4: 799-809, 2012.

182. Zhu YD, Wang L, Sun C, et al: Distinctive microRNA signature is associated with the diagnosis and prognosis of acute leukemia. Med Oncol [Epub ahead of print] 2011.
183. Tanaka M, Oikawa K, Takanashi M, et al: Down-regulation of miR-92 in human plasma is a novel marker for acute leukemia patients. PLoS One 4: e5532, 2009.

184. Aqeilan RI, Calin GA and Croce CM: miR-15a and miR-16-1 in cancer: discovery, function and future perspectives. Cell Death Differ 17: 215-220, 2010

185. Cammarata G, Augugliaro L, Salemi D, et al: Differential expression of specific microRNA and their targets in acute myeloid leukemia. Am J Hematol 85: 331-339, 2010.

186. Tsang WP and Kwok TT: Let-7a microRNA suppresses therapeutics-induced cancer cell death by targeting caspase-3. Apoptosis 13: 1215-1222, 2008.

187. Calin GA, Dumitru CD, Shimizu M, et al: Frequent deletions and down-regulation of micro-RNA genes miR15 and miR16 at 13 q14 in chronic lymphocytic leukemia. Proc Natl Acad Sci USA 99: 15524-15529, 2002.

188. Pons A, Nomdedeu B, Navarro A, et al: Hematopoiesis-related microRNA expression in myelodysplastic syndromes. Leuk Lymphoma 50: 1854-1859, 2009.

189. Zuo Z, Calin GA, De Paula HM, et al: Circulating microRNAs let-7a and miR-16 predict progression-free survival and overall survival in patients with myelodysplastic syndrome. Blood 118: 413-415, 2011

190. Huang JJ, Yu J, Li JY, Liu YT and Zhong RQ: Circulating microRNA expression is associated with genetic subtype and survival of multiple myeloma. Med Oncol [Epub ahead of print] 2012.

191. Yu DC, Li QG, Ding LXW and Ding YT: Circulating microRNAs: potential biomarkers for cancer. Int J Mol Sci 12: 2055-2063, 2011.

192. Duttagupta R, Jiang R, Gollub J, Getts RC and Jones KE: Impact of cellular miRNAs on circulating miRNA biomarker signatures. PLoS One 6: e20769, 2011.

193. Pritchard CC, Kroh E, Wood B, et al: Blood cell origin of circulating microRNAs: a cautionary note for cancer biomarker studies. Cancer Prev Res (Phila) 5: 492-497, 2012.

194. McDonald JS, Milosevic D, Reddi HV, Grebe SK and AlgecirasSchimnich A: Analysis of circulating microRNA: preanalytical and analytical challenges. Clin Chem 57: 833-840, 2011.

195. Reid G, Kirschner MB and van Zandwijk N: Circulating microRNAs: association with disease and potential use as biomarkers. Crit Rev Oncol Hematol 80: 193-208, 2011.

196. Wang Y,Zheng D, Tan Q, Wang MX and Gu LQ: Nanopore-based detection of circulating microRNAs in lung cancer patients. Nat Nanotechnol 6: 668-674, 2011.

197. Spiegel JC, Lorenzen JM and Thum T: Role of microRNAs in immunity and organ transplantation. Expert Rev Mol Med 13: e37, 2011.

198. Benner SA: Extracellular 'communicator RNA'. FEBS Lett 233: 225-228, 1988

199. D'Alessandra Y, Pompilio G and Capogrossi MC: MicroRNAs and myocardial infarction. Curr Opin Cardiol 27: 228-235, 2012.

200. Ha TY: The role of microRNAs in regulatory T cells and in the immune response. Immune Netw 11: 11-41, 2011. 